\title{
Latent trajectories of internalizing symptoms from preschool to school age: A multi-informant study in a high-risk sample
}

\author{
ANNETTE M. KLEIN, ${ }^{a}$ ANDREA SCHLESIER-MICHEL, ${ }^{a, b}$ YVONNE OTTO, ${ }^{a}$ LARS O. WHITE, ${ }^{a}$ \\ ANNA ANDREAS, ${ }^{a}$ SUSAN SIERAU, ${ }^{a}$ SARAH BERGMANN, ${ }^{a}$ SONJA PERREN, ${ }^{c, d}$ AND KAI VON KLITZING ${ }^{a}$ \\ ${ }^{a}$ University of Leipzig; ${ }^{b}$ Friedrich-Schiller-University of Jena; ${ }^{c}$ University of Konstanz; and ${ }^{d}$ Thurgau University of Teacher \\ Education
}

\begin{abstract}
Recent proposals suggest early adversity sets in motion particularly chronic and neurobiologically distinct trajectories of internalizing symptoms. However, few prospective studies in high-risk samples delineate distinct trajectories of internalizing symptoms from preschool age onward. We examined trajectories in a high-risk cohort, oversampled for internalizing symptoms, several preschool risk/maintenance factors, and school-age outcomes. Parents of 325 children completed the Strengths and Difficulties Questionnaire on up to four waves of data collection from preschool (3-5 years) to school age (8-9 years) and Preschool Age Psychiatric Assessment interviews at both ages. Multi-informant data were collected on risk factors and symptoms. Growth mixture modelling identified four trajectory classes of internalizing symptoms with stable low, rising low-to-moderate, stable moderate, and stable high symptoms. Children in the stable high symptom trajectory manifested clinically relevant internalizing symptoms, mainly diagnosed with anxiety disorders/depression at preschool and school age. Trajectories differed regarding loss/separation experience, maltreatment, maternal psychopathology, temperament, and stress-hormone regulation with loss/separation, temperament, maternal psychopathology, and stress-hormone regulation (trend) significantly contributing to explained variance. At school age, trajectories continued to differ on symptoms, disorders, and impairment. Our study is among the first to show that severe early adversity may trigger a chronic and neurobiologically distinct internalizing trajectory from preschool age onward.
\end{abstract}

Internalizing symptoms and disorders are among the most prevalent psychiatric complaints throughout the life span (Vasey, Bosmans, \& Ollendick, 2014). From preschool age onward, ample studies demonstrate that internalizing problems show moderate stability or tend to increase, and often inflict substantial impairment (Bufferd, Dougherty, Carlson, Rose, \& Klein, 2012; Côté et al., 2009; Egger \& Angold, 2006; Klein, Otto, Fuchs, Reibiger, \& von Klitzing, 2015; von Klitzing et al., 2014). Recently, scholars have proposed that exposure to severe early adversity sets individuals on a fundamentally distinct pathway of chronic levels of psychopathology and altered neurobiology (e.g., Teicher \& Samson, 2013). However, to date, few studies on internalizing problems in young children tackle these issues (Cicchetti \& Natsuaki, 2014). Rather, most longitudinal work beginning in early childhood has focused on predictors of increases in internalizing symptoms as a whole rather than predictors of several distinct and empirically derived time

This study was supported by German Research Foundation Grants KL2315/ 1-1, KL2315/1-2, and KL2338/1-2 (to K.V.K. and A.M.K.) and German Federal Ministry of Education and Research Grant 01KR1201A. The authors thank the Public Health Department of the City of Leipzig for cooperating in this study, and all families for participating repeatedly.

Address correspondence and reprint requests to: Annette M. Klein, Department of Child and Adolescent Psychiatry, Psychotherapy, and Psychosomatics, University of Leipzig, Liebigstraße 20a, 04103 Leipzig, Germany; E-mail: annette.klein@medizin.uni-leipzig.de.

(D) Author's ORCID: https://orcid.org/0000-0001-8246-4666 courses of these symptoms over multiple assessment waves ("trajectories"). Of the few studies analyzing trajectories in children, emerging evidence suggests that internalizing problems can stably persist at low, moderate, or high levels for some children, or change for better or worse for others (e.g., Nantel-Vivier, Pihl, Côté, \& Tremblay, 2014; Whalen et al., 2016). With the help of recent advances in data analysis (Muthén, 2004), it is now possible to chart alternate developmental courses of internalizing problems and identify contributing risk factors. The current 5-year longitudinal study therefore considers the predictive value of a broad array of factors at multiple levels of analysis for different trajectories of internalizing problems beginning at preschool age through middle childhood. As a point of departure for this study, we drew on current multilevel approaches to internalizing problems (e.g., Hankin, 2012; Hastings et al., 2015; Mills et al., 2012) and familial adversity and maltreatment (Cicchetti \& Lynch, 1993; Cicchetti \& Valentino, 2006; Schleider \& Weisz, 2017) to identify potential predictors for differential longitudinal courses of internalizing symptoms. These models attempt to integrate psychological, social, and neurobiological domains so as to do justice to the multifactorial nature of internalizing problems.

\section{Trajectories of Internalizing Symptoms}

A burgeoning research database has begun to delineate multiple longitudinal patterns of stability and change in internalizing or 
specific anxiety and depressive symptoms in preschool age (Bayer et al., 2012; Côté et al., 2009) or from preschool to school age (Davis, Votruba-Drzal, \& Silk, 2015; Dekker et al., 2007; Fanti \& Henrich, 2010; Nantel-Vivier et al., 2014; Sterba, Prinstein, \& Cox, 2007; Weeks et al., 2014; Whalen et al., 2016). The exact number of internalizing trajectory classes identified by these studies varies considerably between three and six (Bayer et al., 2012; Côté et al., 2009; Davis et al., 2015; Dekker et al., 2007; Fanti \& Henrich, 2010; Nantel-Vivier et al., 2014; Sterba et al., 2007; Weeks et al., 2014; Whalen et al., 2016). Predominantly, this work has identified classes of internalizing symptoms with stable low, moderate, and high symptom levels (e.g., Bayer et al., 2012; Fanti \& Henrich, 2010; Nantel-Vivier et al., 2014; Weeks et al., 2014; Whalen et al., 2016). In several studies, additional classes with increasing or decreasing symptoms were identified (e.g., Côté et al., 2009; Sterba, 2007). Some studies additionally distinguish trajectories for boys and girls, reporting varying proportions and/or courses, among others (Dekker et al., 2007; Sterba et al., 2007; Whalen et al., 2016).

The main strength of these pioneering studies mostly lies in large and representative samples. However, as is typically the case for community-based research (cf. Rutter, Kumsta, Schlotz, \& Sonuga-Barke, 2012), either samples merely included a small fraction of children in the high symptom trajectory (Davis et al., 2015; Weeks et al., 2014) or children in this trajectory, on average, scored outside the clinical range (Côté et al., 2009; Fanti \& Henrich, 2010; Nantel-Vivier et al., 2014; but see Davis et al., 2015; Whalen et al., 2016). In light of this predominance of community samples, there is a strong demand for research investigating trajectories in clinical or high-risk cohorts (cf. Sterba et al., 2007).

The aim of our longitudinal study was to fill this research gap by examining trajectory classes of internalizing symptoms from preschool age to school age in a community cohort oversampled for internalizing symptoms. In so doing, we expected to detect a clinical-risk trajectory class besides other trajectories commonly identified in the literature. In a second step, we sought to determine factors at multiple levels of analysis that increase the risk that a child will belong to high-risk trajectories and verify the clinical-level risk using diagnostic interviews as outcome measures.

\section{Risk Factors and Maintenance Factors for Internalizing Symptoms}

Given the multifactorial nature of internalizing disorders (Hankin, 2012), we address risk factors from multiple levels of analysis: social and interpersonal factors (e.g., stressful life events and maternal mental health problems), individual child factors (e.g., temperament), and intermediary processes (e.g., biological stress physiology).

\section{Social and interpersonal factors}

A number of studies report that stressful life events (e.g., loss of/separation from a significant person, transitions, and accidents) predict depression and anxiety both in childhood (Bufferd et al., 2014; Edwards, Rapee, \& Kennedy, 2010; Furniss, Beyer, \& Müller, 2009; Luby, Belden, \& Spitznagel, 2006; Scheuer et al., 2016) and in adolescence (Kim, Conger, Elder, \& Lorenz, 2003). Developmental studies offer strong support that stressful life events, especially in the first years of life, can exert protracted effects (for a review, see O'Connor, 2016). Similarly, the presence of maltreatment in early childhood has been highlighted as one of the most detrimental risk factors for an individual's psychosocial development (Cicchetti \& Toth, 2015; Teicher $\&$ Samson, 2013). Children with early maltreatment experiences have a greater likelihood of manifesting internalizing psychopathology across different developmental stages (Manly, Kim, Rogosch, \& Cicchetti, 2001; Robinson et al., 2009). Several studies demonstrated long-term effects of early maltreatment experiences on both the magnitude (Godinet, Li, \& Berg, 2014; Keiley, Howe, Dodge, Bates, \& Pettit, 2001; Kim \& Cicchetti, 2006; van der Vegt, van der Ende, Ferdinand, Verhulst, \& Tiemeier, 2009) and the increase (Godinet et al., 2014; Keiley et al., 2001; Kim \& Cicchetti, 2006; Thompson \& Tabone, 2010) of internalizing symptoms. Moreover, two recent studies on latent class trajectories of internalizing symptoms showed that more pervasive maltreatment and early childhood social adversity (including physical and sexual abuse) predicts belonging to more pathological anxiety/depressive symptoms groups relative to low-symptom groups (Lauterbach \& Armour, 2016; Whalen et al., 2016). However, despite abundant work on adults demonstrating a strong impact of child maltreatment on the chronicity, relapse rates, and treatment resistance of internalizing disorders (Teicher \& Samson, 2013), studies on the predictive value of child maltreatment on distinct internalizing trajectories among children are still scarce.

Mental health problems of caregivers, especially maternal depression, have also been identified as important risk factors for internalizing psychopathology in offspring (for a metaanalytic review, see Goodman et al., 2011). For example, parental psychopathology predicted internalizing symptoms in preschoolers (Badanes, Watamura, \& Hankin, 2011), as well as depressive symptoms and depression in children and adolescents (Bufferd et al., 2014; Klasen et al., 2015; Luby, Gaffrey, Tillman, April, \& Belden, 2014; Murray et al., 2011; Otto et al., 2016; Reinfjell, Kårstad, Berg-Nielsen, Luby, \& Wichstrøm, 2016). Likewise, maternal psychosocial stress can raise children's risk of developing internalizing symptoms or disorders (Mesman \& Koot, 2000; Wadsworth \& Achenbach, 2005). Several studies analyzing symptom trajectories show that maternal depressive symptoms or having an affected close relative robustly predicts children's membership in high internalizing trajectories (Côté et al., 2009; Sterba et al., 2007; Weeks et al., 2014; Whalen et al., 2016). Maternal mental health problems should therefore be examined when analyzing contributing factors for distinct internalizing symptom trajectories. 


\section{Individual factors: Children's temperament}

Considerable research has examined individual differences in temperament as vulnerabilities to internalizing symptoms (for a review, see Compas, Connor-Smith, \& Jaser, 2004; Hankin, 2012). Rothbart, Ahadi, Hershey, and Fisher (2001) propose three broad temperament dimensions: negative affectivity, surgency, and effortful control. High negative affectivity is consistently associated with childhood internalizing symptoms and disorders (Davis et al., 2015; Nigg, 2006) and increases in depression (Reinfjell et al., 2016). Moreover, low effortful control (i.e., self-regulation) and low surgency (i.e., extraversion and positive affectivity) are associated with internalizing symptoms (Gartstein, Putnam, \& Rothbart, 2012; Muris \& Ollendick, 2005), although effects are lower or less consistent.

\section{Stress hormone system}

Finally, multilevel models take into account key neurobiological risk mechanisms for developmental psychopathology, such as altered hypothalamic-pituitary-adrenal (HPA) axis functioning (Bush \& Boyce, 2014; Gunnar \& Quevedo, 2007; Hankin, 2012). A normally functioning HPA axis provides an adaptive stress-response system that upregulates to meet the metabolic demands of the individual under perceived threat, but is efficiently downregulated in a safe environment ("allostasis"). However, chronic inescapable threat that exceeds coping capacities and enhances risk for internalizing disorders may lastingly shift the basal functioning and threat reactivity of the HPA axis (McEwen, 1998).

Research on school-age and adolescent samples reports both hyper- and hyposecretory patterns in relation to internalizing problems. Thus, ample studies document higher morning and basal cortisol as well as enhanced cortisol reactivity to pharmacological and social challenge in 8- to 15-year-olds with internalizing symptoms (Booij, Bouma, de Jonge, Ormel, \& Oldehinkel, 2013; Cicchetti \& Rogosch, 2001; Dietrich et al., 2013; Harkness, Stewart, \& Wynne-Edwards, 2011; Lopez-Duran, Kovacs, \& George, 2009; Ruttle et al., 2011). However, subgroup analyses within many of these studies (Booij et al., 2013; Harkness et al., 2011; Ruttle et al., 2011), as well as data on persistent clinical-level childhood internalizing disorders (Bae et al., 2015), reveal an opposite pattern of attenuated basal and stress-induced cortisol secretion among children with especially chronic or severe internalizing symptoms and disorders.

To account for these opposing patterns, scholars have proposed various factors (Doom \& Gunnar, 2013), including timing and chronicity of allostatic load (Miller, Chen, \& Zhou, 2007), developmental factors (Hankin, 2012), and measurement type, including stressor paradigms, of HPA axis (re-)activity (Gunnar, Talge, \& Herrera, 2009). With regard to timing and chronicity of allostatic load, one key proposal holds that severe stress may initially give rise to hypersecretion as the organism attempts to overcome the challenge. As these attempts continually fail, however, persistent stress may over time result in a lasting downregulation of the HPA axis, potentially owing to increased glucocorticoid receptor sensitivity or adaptations at the level of the pituitary (Fries, Hesse, Hellhammer, $\&$ Hellhammer, 2005). For example, recent work suggests that early and chronic childhood maltreatment, one of the key risk factors for internalizing problems (see above), initially engenders a pattern of hypersecretion followed by pronounced hyposecretion of cortisol (e.g., Trickett, Noll, Susman, Shenk, \& Putnam, 2010; White et al., 2017). Particularly in environments that involve insufficiently sensitive and responsive care, emergence of hypocortisolism may reflect an "evolutionarily conservative" strategy (Fisher, 2017) as children lack the interpersonal support otherwise provided by caregivers and are left to their own devices to regulate stress.

Developmental factors may also play a crucial role. In particular, findings indicate that while prepubertal internalizing problems may predispose children to hyporesponsivity, postpubertal depression involves the HPA hyperresponsivity typically detected in adults (Badanes et al., 2011; Hankin, 2012; Hankin, Badanes, Abela, \& Watamura, 2010). Accordingly, Badanes et al. (2011) suggest that prior to the onset of puberty, substantial and uncontrollable stressors (e.g., adverse family environment) elicit attenuated cortisol reactivity in an attempt to protect the child from the health risks and dangers incurred by mounting a fully developed fight or flight response. By contrast, during puberty children and adolescents may gain more resources to actively engage or escape these stressors, rendering HPA axis hyperactivation a more adaptive stress response (Badanes et al., 2011).

Despite ample data on older children, studies on the link between HPA axis functioning and internalizing symptoms in younger children are still scarce. Some evidence suggests that attenuated cortisol secretion may predispose preschoolers to concurrent and increasing internalizing symptoms (Badanes et al., 2011; Hankin et al., 2010; Hastings et al., 2015, von Klitzing et al., 2012). Yet, whether these attenuated cortisol response patterns also reflect a specific marker of particularly stable internalizing trajectories in early childhood is currently still unknown.

\section{Outcomes of Trajectory Groups}

Besides risk factors that underpin distinct developmental trajectories, we also aimed to examine developmental outcomes of trajectory groups, that is, anxiety and depressive symptoms, anxiety disorders/depression at the diagnostic level, social impairment, as well as externalizing symptoms and social competences. In so doing, our main objective was to confirm that children in high-risk trajectories would show persistent and clinically relevant difficulties.

Previous work on trajectories of internalizing symptoms reports that class membership has predictive value for several specific and nonspecific negative outcomes. For instance, Dekker et al. (2007) showed that youth following an elevated trajectory of depressive symptoms also exhibited higher mean 
levels of depressive and general psychiatric symptoms in young adulthood. Likewise, membership of high internalizing symptom trajectories predicted preadolescent (Sterba et al., 2007) and adolescent depressive symptoms (Toumbourou, Williams, Letcher, Sanson, \& Smart, 2011). Yet, to the best of our knowledge, no studies to date have used diagnostic interviews to examine anxiety disorders/depression as outcomes of distinct internalizing trajectories during elementary school age.

Moreover, internalizing and externalizing symptoms tend to co-occur, and children who exhibit high internalizing symptoms might show high levels of externalizing symptoms as well (Achenbach, Conners, Quay, Verhulst, \& Howell, 1989). Individuals with co-occurring problems show greater functional interference in their daily lives (Newman, Moffitt, Caspi, \& Silva, 1998), potentially rendering comorbid externalizing symptoms an important prognostic marker of future internalizing pathways.

Furthermore, internalizing symptoms, including depression and anxiety, have been found to be associated with social skills deficits (e.g., Coplan \& Ooi, 2013; Gazelle \& Ladd, 2003; Hawker \& Boulton, 2000; Wichstrøm, Belsky, \& Berg-Nielsen, 2013). Appropriately regulated prosociality is associated with healthy development whereas high anxiety or depressive symptoms might prevent children from developing adequate social skills. Earlier studies showed that internalizing symptoms are associated with deficits in self-oriented social competences (e.g., assertiveness and social participation) in contrast to other-oriented social skills (e.g., prosocial and cooperative behavior; Groeben, Perren, Stadelmann, \& von Klitzing, 2011; Perren, Forrester-Knauss, \& Alsaker, 2012). However, prior work on internalizing trajectories presents inconsistent findings: While Korhonen et al. (2014) showed that children in high internalizing trajectories exhibited lower social competences, other work suggests that social skills deficits are only present in children with comorbid internalizing and externalizing symptoms (Fanti \& Henrich, 2010) or more complex patterns emerged (Nantel-Vivier et al., 2014). Yet, to the best of our knowledge, self- and other-oriented social competences as distinct dimensions have not been examined as outcomes of internalizing trajectories so far.

Beyond this, in order to determine clinical significance, it is of utmost importance to analyze whether internalizing trajectory classes predict impairment of the child at school age. Some children may have internalizing symptoms, but these do not interfere with their everyday lives (Goodman, 1999). In contrast, other children may show distress and social impairment, potentially resulting in difficulties resolving developmental tasks. Previous studies have shown that only $10 \%-$ $29 \%$ of preschool- and school-age children with mental health problems receive professional help (Hintzpeter et al., 2015; Shivram et al., 2009; Wichstrøm, Belsky, Jozefiak, Sourander, \& Berg-Nielsen, 2014). Finally, difficulties and impairment of the child and/or burden to families also predict mental health care use (Ford, Hamilton, Meltzer, \& Good- man, 2008; Goodman, 1999; Hintzpeter et al., 2015; Wichstrøm et al., 2014), though few or no studies relate this factor to internalizing trajectories in children. It is therefore highly relevant to assess both social impairment and mental health care use as outcomes.

\section{Objectives}

To date, in previous work on distinct internalizing trajectories, community samples are overrepresented as compared to selected high-risk samples. Therefore, this raises the question of whether results also apply to a clinically relevant range. Moreover, several studies examine potential risk factors predicting class memberships and outcomes of trajectory classes. Yet, few or no studies have investigated a comprehensive set of risk/maintenance factors at multiple levels, including neurobiological stress reactivity, and several outcomes to inform clinical relevance of (persistent) difficulties.

To fill these research gaps, the first objective of this study was to examine trajectories of internalizing symptoms from preschool to school age in a high-risk community sample oversampled for internalizing symptoms. Based on previous research, we anticipated three to four distinct trajectory classes with stable low, moderate, and high internalizing symptoms, and possibly, one group with increasing internalizing symptoms. In light of our specific sample, we expected that the high internalizing symptoms group would show, on average, symptoms in a clinical range. Due to the inconsistencies regarding gender effects, we explored gender differences without making explicit predictions. In addition, we examined the presence of anxiety disorders/depression derived from clinical interviews to inform clinical relevance at preschool age.

Second, we aimed to identify risk factors for unfavorable courses of internalizing symptoms. Here, we assessed stressful life events, maltreatment, maternal mental health problems, child temperament, and neurobiological stress regulation. Based on the extant literature (e.g., Lauterbach \& Armour, 2016; Weeks et al., 2014; Whalen et al., 2016), we predicted that a higher proportion of children in highrisk trajectories (i.e., with high or increasing levels of internalizing symptoms) would be exposed to early stressful life events and maltreatment experiences. We also expected children in high-risk trajectories to have mothers with more mental health problems, to show higher negative affectivity, and to exhibit more cortisol dysregulation at preschool age. Finally, we explored the relative contribution of these predictors (i.e., in the presence of other predictors) on trajectories of internalizing symptoms.

Third, we sought to examine the long-term outcome of children in distinct trajectory classes, that is, anxiety/depressive symptoms and disorders, social impairment, mental health care use, as well as externalizing symptoms and social competences at middle elementary school age. To this end, we used reports of multiple informants (parents, teacher, and child) to determine whether children in high-risk internal- 
izing trajectories show persistent and clinically relevant difficulties. Based on previous work (e.g., Sterba et al., 2007; Whalen et al., 2016), we expected to find higher symptom load (both anxiety/depressive and externalizing symptoms), social impairment, and lower self-oriented social competences (but not other-oriented social competences) in high-risk compared to low-risk trajectories. Extending previous work, we investigated presence of anxiety disorders/depression and mental health care use at school age, anticipating higher proportions of disorders and mental health care use in highrisk trajectories relative to low-risk trajectories.

\section{Method}

\section{Study design and sample}

The present study was designed to prospectively investigate trajectories of clinically relevant internalizing symptoms in children from preschool to elementary school age. We screened 1,738 3- to 5-year-olds from the community for internalizing symptoms by asking parents to complete the Strengths and Difficulties Questionnaire (SDQ; Goodman, 1997). For the longitudinal study, we oversampled children with high scores on the emotional symptoms subscale (referred to hereafter as internalizing symptoms), that is, children with internalizing symptoms in borderline or abnormal range ( $n=130,40.0 \%$ ), and recruited control children with scores in the normal range on all problem scales of the SDQ. Response rates were $74.4 \%$ in the internalizing symptoms group and $86.7 \%$ in the control group. Both groups were comparable in terms of gender distribution, age, and socioeconomic background. For the present analyses, data from 325 children were available. These were primarily of European Caucasian origin (98\%; 2\% mixed, Asian, or Hispanic background).

Participating families provided data on up to four waves of data collection, twice at preschool age (Wave 1: $M_{\text {age }}=4$ years, 2 months [4;2]; $S D=5.52$ months; Wave $2: M_{\text {age }}=$ $5 ; 2 ; S D=6.10$ ), at early elementary school age (Wave 3: $\left.M_{\text {age }}=7 ; 4 ; S D=3.07\right)$, and at middle elementary school age (Wave 4: $M_{a g e}=8 ; 5 ; S D=3.28$ ). Families predominantly attended all four waves $(n=204 ; 62.8 \%)$, or three waves $(n=64 ; 19.7 \%)$, while a minority only attended two waves $(n=54 ; 16.6 \%)$, or a single wave $(n=3 ; 0.9 \%)$. Maternal education was higher in families who participated at all four waves of data collection than in those who attended only one to three waves, $F(1,310)=9.96, p=.002, \eta_{\mathrm{P}}^{2}=0.031$, but the two groups did not differ significantly on gender distribution, household income, or domestic situation (all ps $>$ .11). Table 1 shows sociodemographic characteristics of the total sample and of families participating in all four waves of data collection.

Except for the baseline screening, all assessments took place in the research laboratories of the Department of Child and Adolescent Psychiatry, Psychotherapy, and Psychosomatics, University of Leipzig. Mothers completed several measures regarding their child, their own mental health, and the family situation. One of the parents, mostly mothers, also took part in clinical interviews regarding their child, once when the child was of preschool age (Wave 2) and once when the child was of school age (Wave 4). Meanwhile, the children were interviewed separately. Table 2 gives an overview of the waves of data collection and the measures assessed.

Participation in the study was voluntary, and families received financial compensation at all waves. Caregivers and children provided informed consent and assent, respectively,

Table 1. Sociodemographics of the total sample, $N=325$, and of families participating in all four waves of data collection, $n=204$

\begin{tabular}{lcc}
\hline \hline & $\begin{array}{c}\text { Total sample, } \\
N=325 \\
n(\%)\end{array}$ & $\begin{array}{c}\text { Participants all waves, } \\
n=204 \\
n(\%)\end{array}$ \\
\hline Females (percentage) & $158(48.6 \%)$ & $98(48.0 \%)$ \\
Education mother & $36(11.1 \%)$ & $18(8.8 \%)$ \\
Lower secondary school & $109(33.5 \%)$ & $61(29.9 \%)$ \\
Upper secondary school & $46(14.2 \%)$ & $34(16.7 \%)$ \\
High school diploma & $121(37.2 \%)$ & $87(42.6 \%)$ \\
University degree & $13(4.0 \%)$ & $4(2.0 \%)$ \\
Missing & $102(31.4 \%)$ & $69(33.8 \%)$ \\
Household income & $171(52.6 \%)$ & $127(62.3 \%)$ \\
Low (<€2000/month) & $4(1.2 \%)$ & $3(1.5 \%)$ \\
Medium (€2000 to $<€ 6000 /$ month) & $48(14.8 \%)$ & $5(2.4 \%)$ \\
High ( $>€ 6000 /$ month) & & $161(78.9 \%)$ \\
Missing & $219(67.4 \%)$ & $43(21.1 \%)$ \\
Domestic situation & $62(19.1 \%)$ & - \\
Lives with both parents & $44(13.5 \%)$ & \\
Lives with one parent & & \\
Other social situation/missing & & \\
\hline \hline
\end{tabular}


Table 2. Overview of waves (W) of data collection, age (years, months), and measures assessed

\begin{tabular}{|c|c|c|c|c|}
\hline \multirow[b]{2}{*}{ Measures } & \multirow[b]{2}{*}{$\begin{array}{l}\text { Screening } \\
\quad W 1: \\
M_{\text {age }}=4 ; 2\end{array}$} & \multicolumn{3}{|c|}{ Detailed assessments } \\
\hline & & $\begin{array}{c}W 2: \\
M_{\text {age }}=5 ; 2\end{array}$ & $\begin{array}{c}\text { W3: } \\
M_{\text {age }}=7 ; 4\end{array}$ & $\begin{array}{c}\text { W4: } \\
M_{\text {age }}=8 ; 5\end{array}$ \\
\hline \multicolumn{5}{|l|}{ Trajectory groups/validity } \\
\hline $\begin{array}{l}\text { Internalizing symptoms, mother report (SDQ 4-16) } \\
\text { Internalizing symptoms, father and teacher report (SDQ 4-16) } \\
\text { Anxiety disorder/depression (PAPA) }\end{array}$ & $\mathrm{x}$ & $\begin{array}{l}\mathrm{X} \\
\mathrm{X} \\
\mathrm{X}\end{array}$ & $\mathrm{x}$ & $\mathrm{x}$ \\
\hline \multicolumn{5}{|l|}{ Risk and maintenance factors } \\
\hline $\begin{array}{l}\text { Stressful life events before age } 3 \text { (PAPA)—retrospective assessment } \\
\text { Maltreatment experiences before age } 3 \text { (MMCI, MCS)—retrospective } \\
\text { assessment } \\
\text { Maternal mental health problems (PHQ) } \\
\text { Child temperament (CBQ-VSF) } \\
\text { Neurobiological stress regulation (cortisol reactivity) }\end{array}$ & & $\begin{array}{l}\mathrm{X} \\
\mathrm{X} \\
\mathrm{X}\end{array}$ & $\mathrm{x}$ & $\mathrm{x}$ \\
\hline \multicolumn{5}{|l|}{ Outcome variables at elementary school age } \\
\hline $\begin{array}{l}\text { Anxiety symptoms, parent report (SCARED) } \\
\text { Depressive symptoms, parent report (CES-DC) } \\
\text { Distress and social impairment (SDQ impact supplement) } \\
\text { Child-reported internalizing and externalizing symptoms (BPI) } \\
\text { Externalizing symptoms, parent report (SDQ) } \\
\text { Social competences, teacher report (SOCOMP) } \\
\text { Anxiety disorder/depression (PAPA) } \\
\text { Mental health care use }\end{array}$ & & & & $\begin{array}{l}\mathrm{x} \\
\mathrm{x} \\
\mathrm{x} \\
\mathrm{x} \\
\mathrm{x} \\
\mathrm{x} \\
\mathrm{x} \\
\mathrm{x}\end{array}$ \\
\hline
\end{tabular}

Note: SDQ 4-16, Strengths and Difficulties Questionnaire, Ages 4-16. MMCI, Maternal Maltreatment Classification Interview. MCS, Maltreatment Classification System. PHQ, Patient Health Questionnaire. CBQ-VSF, Children's Behavior Questionnaire-Very Short Form. SCARED, Screen for Child Anxiety Related Emotional Disorders. CES-DC, Center for Epidemiologic Studies Depression Scale for Children. BPI, Berkeley Puppet Interview. SOCOMP, Self- and Other-Oriented Social Competences Questionnaire. PAPA, Preschool Age Psychiatric Assessment.

after receiving written and/or oral information about the study. Ethical approval was obtained from the institutional review board of the Medical Faculty of the University of Leipzig.

\section{Measures}

\section{Internalizing trajectories and disorders.}

Internalizing symptoms. The emotional symptoms subscale of the SDQ (Goodman, 1997; Klasen, Woerner, Rothenberger, \& Goodman, 2003), completed by mothers, fathers, and teachers, served as a measure of internalizing symptoms. The subscale comprises five items gauging anxiety, sadness, as well as psychosomatic complaints, scored as not true (0), somewhat true (1), or certainly true (2) in the last 6 months (sum score 0-10). Based on recommended cutoffs, internalizing symptom scores below 4 are categorized as "normal," scores of 4 as "borderline," and scores of 5 and above as "abnormal" (Woerner, Becker, \& Rothenberger, 2004). Adequate validity and reliability was established in several studies (e.g., Goodman, 2001; Klein, Otto, Fuchs, Zenger, \& von Klitzing, 2013; Stone, Otten, Engels, Vermulst, \& Janssens, 2010), and our data also yielded moderate reliability across different informants (mother, father, and teacher) and waves (Cronbach $\alpha=$ 0.69-0.75). The internalizing symptoms scales completed by mothers at all four waves served as an index to derive the trajectory groups. The internalizing symptoms scales completed by fathers and teachers at preschool age were analyzed to evaluate validity.

Anxiety disorder/depression. To determine the presence/ absence of DSM-IV diagnoses, we interviewed one of the parents (85\%-93\% mothers) using the Preschool Age Psychiatric Assessment (PAPA; Egger \& Angold, 2004) at preschool age (Wave 2) and again at elementary school age (Wave 4; this assessment served as outcome). The PAPA is a 2- to 3-hr interviewer-based structured psychiatric assessment for 3- to 8-year-olds. Parents reported intensity, frequency, duration, and onset of symptoms for the last 3 months (primary period) to allow interviewers to assess the presence or absence of diagnoses. Symptom scores and categorical diagnoses were generated using algorithms designed expressly for the PAPA applying the Research Diagnostic CriteriaPreschool Age (Task Force on Research Diagnostic Criteria: Infancy and Preschool, 2003). Under the guidance of the PAPA authors, our research group developed a German version of the PAPA. Prior to assessment, a senior clinical scientist who was trained by the PAPA group instructed all interviewers and supervised their pretest interviews. The following PAPA modules were assessed: oppositional defiant disorder, conduct disorder, depression, social and specific phobia, general anxiety disorders, and separation anxiety disorder. Interviewers administered an electronic version on 
tablet PCs. Interrater reliability was established for 15 doublecoded videos ( $\kappa$ s ranged from .63 to 1.00). We also rated clinically relevant depressed/irritable mood (subthreshold dysthymia), that is, depressed mood or looking unhappy or being touchy, easily annoyed, or irritable for at least half of the primary period.

Based on subcategories established in the literature (von Klitzing et al., 2014), we used the PAPA to derive three diagnostic groups according to presence/absence of anxiety disorders and depression (i.e., subthreshold dysthymia and/or depression diagnosis): no disorder (i.e., absence of any disorder), a "pure" anxiety disorder diagnosis, and depression (with or without comorbid anxiety).

\section{Risk and maintenance factors.}

Stressful life events. Mothers indicated whether their child had ever experienced a set of stressful life events, and if yes, when the events occurred (18 items based on the life events modules of the PAPA; Egger \& Angold, 2004). The list of events comprised transitions in the child's environment (e.g., moving away or nursery/kindergarten transition), loss of/separation from a significant person (e.g., death of a significant person, separation or divorce of parents, or extended unavailability of a caregiver), or threat to the child's physical health and/or life (e.g., vehicle accident, fire, or almost drowning). To assess predictive value for trajectories, we focused on whether or not life events of transitions, loss, and threat had occurred before the age of 3 (retrospectively assessed from PAPA at middle elementary school age, Wave 4).

Maltreatment classification. We interviewed caregivers using the Maternal Maltreatment Classification Interview (Cicchetti, Toth, \& Manly, 2003). Interviews were scored using the Maltreatment Classification System (MCS; Barnett, Manly, \& Cicchetti, 1993), by raters trained by one of the MCS authors. The MCS is a highly accurate and validated standardized system to evaluate maltreatment events. To assess predictive value for trajectories, we focused on whether or not the child had experienced any of the following subtypes before age 3: sexual and physical abuse, neglect (including failure to provide and lack of supervision), or emotional maltreatment (retrospectively assessed at early elementary school age, Wave 3). Independent, blind raters double-coded $20 \%$ of the interviews to compute interrater agreement (Cohen $\kappa$ between .78 and 1.00).

Maternal mental health problems. At preschool age, mothers completed the Patient Health Questionnaire (Spitzer, Kroenke, Williams, \& Patient Health Questionnaire Primary Care Study Group, 1999), a widely accepted, valid, and reliable instrument to screen for the presence and severity of frequent mental health problems. We used the following subscales: depressive symptoms ( 9 items; Cronbach $\alpha=0.84$ ), somatization (15 items; Cronbach $\alpha=0.74$ ), and stress (10 items; Cronbach $\alpha=0.73)$.
Children's temperament. When their child was at preschool age, mothers completed the Children's Behavior Questionnaire-Very Short Form (Rothbart et al., 2001), a well-established parent-report measure of temperament for children aged 3 to 8 years (Putnam \& Rothbart, 2006). We used the following subscales: surgency (measuring positive affectivity; 12 items; $\alpha=0.68)$, negative affectivity (12 items; $\alpha=0.75$ ), and effortful control (measuring self-regulation; 12 items, $\alpha=0.71$ ).

Neurobiological stress regulation (cortisol reactivity). At the first detailed preschool-age assessment, children provided four saliva samples ("Salivette ${ }^{\circledR}$ for Cortisol", Sarstedt, Nümbrecht, Germany) to measure cortisol reactivity to an age-appropriate challenging story-telling task, the MacArthur Story Stem Battery (MSSB; Emde, Wolf, \& Oppenheim, 2003). The MSSB has proven useful for assessment of HPA axis responses at preschool age (Hatzinger et al., 2007; von Klitzing et al., 2012). For the MSSB, children are exposed to a set of standardized, developmentally appropriate beginnings of stressful stories to elicit relevant play narratives (for details, see, e.g., von Klitzing, Kelsay, \& Emde, 2003). The four saliva samples were collected (a) at the beginning of the assessment; (b) after $20 \mathrm{~min}$, that is, immediately before starting the MSSB; (c) 40 min later, that is, after completing the MSSB; and (d) after an additional 25 min (following a relaxation phase). Given the circadian rhythm of cortisol, we arranged the assessments in the early afternoon. Due to scheduling issues of the participating families, a minority of appointments (18\%) took place in the morning. To account for this, we included time of first saliva sampling as a covariate in a preliminary analysis. As this analysis yielded comparable results, we only reported the uncontrolled findings to facilitate post hoc comparisons between trajectory classes. Further, we asked caregivers regarding medication of children and excluded the cases from cortisol analyses, if children were medicated with substances known to interact with cortisol (e.g., corticosteroid medication).

Saliva samples were centrifuged and aliquoted for the measurement of cortisol reactivity. Samples were stored at $-80{ }^{\circ} \mathrm{C}$ until cortisol assessment. Cortisol levels were determined by a saliva-specific luminescence immunoassay (IBL International $\mathrm{GmbH}$, Hamburg, Germany). The assay was conducted with $50 \mu \mathrm{L}$ of saliva according to the specifications and protocols provided by the manufacturer. Before analyses, we excluded outliers $( \pm 3 S D)$. The area under the curve with respect to ground was computed as an index for the total reactivity of cortisol (sum of trapezoidal areas from Sample 1 to Sample 4; see Pruessner, Kirschbaum, Meinlschmid, \& Hellhammer, 2003). Cortisol data were log-transformed.

\section{Outcome variables at elementary school age.}

Anxiety symptoms. Mothers and fathers completed the 41item Screen for Child Anxiety Related Emotional Disorders (SCARED; Birmaher et al., 1997, 1999). Parents rated the fre- 
quency of anxiety symptoms in the last 3 months on a 3point-scale from 0 (almost never) to 2 (often). Ratings were summed to a total anxiety score. A score of 25 or higher indicates abnormality (Birmaher et al., 1999). Validity and reliability were established in several studies (Birmaher et al., $1997,1999)$. Total anxiety scores yielded good internal consistency both for mother reports $(\alpha=0.89)$ and father reports $(\alpha=0.87)$, and both were significantly correlated $(r=.54$, $p<.001)$. If both were available $(80.57 \%)$, total anxiety scores of mothers and fathers were averaged ("parents").

Depressive symptoms. Mothers and fathers completed the Center for Epidemiologic Studies Depression Scale for Children (CES-DC; Barkmann, Erhart, Schulte-Markwort, \& BELLA Study Group, 2008; Radloff, 1977). The CES-DC is a 20 -item screening instrument assessing emotional, cognitive, and behavioral aspects of depression over the previous week. Items are rated from 0 (not at all), to 3 (a lot) and summed to a total depression score (0-60). Based on the recommended cutoffs, a total score of 15 and higher indicates depression (Fendrich, Weissman, \& Warner, 1990). Total depression scores yielded good internal consistency for the mother report $(\alpha=0.82)$ and the father report $(\alpha=0.80)$, and both were significantly correlated $(r=.57, p<.001)$. If both were available (82.52\%), total depression scores of mothers and fathers were averaged ("parents").

Distress and social impairment. Moreover, mothers and fathers completed the Impact Supplement of the SDQ (Goodman, 1999). It inquires whether parents perceive their child to have difficulties (regarding emotions, concentration, behavior, or relationships), and if yes, whether these lead to any distress and/or interfere with their child's everyday life (at home, with friends, learning, and leisure activities). Following Goodman (1999), we computed total impact scores (0-10) by aggregating the distress and four impairment scales using the 3-point scales from 0 (not at all/only a little) to 2 (a great deal). The mothers' and fathers' reports were significantly correlated $(r=.67, p<.001)$. If both were available (89.34\%), mother and father reports were averaged ("parents").

Child-reported internalizing and externalizing symptoms. To assess children's reports of internalizing and externalizing symptoms, we used the Berkeley Puppet Interview (BPI; Measelle, Ablow, Cowan, \& Cowan, 1998), an interviewing technique designed to elicit self-perceptions from 3.5- to 8year-olds (Stone et al., 2013). The interviewer introduces two identical hand puppets to the child that make two opposite statements (e.g., "I am a sad child"_- "I am not a sad child"). The puppets then ask the child to indicate how he or she behaves or feels. Interviews were videotaped and scored on 7-point scales (approval of the negative aspect vs. approval of the positive aspect) by raters blind to all other data. Interviewers were trained and gained interrater reliability with an authorized senior researcher, herself trained by the BPI developers. We used the internalizing symptoms scale
(20 items, subscales: depression $=7$ items; anxiety $=7$ items; and social inhibition $=6$ items), as well as the externalizing symptoms scale (13 items; oppositional defiant $=6$ items and overt hostility $=7$ items). A subset of interviews (12.7\%) were double-coded, yielding an excellent interrater reliability (intraclass correlation coefficient $=0.99$ for each internalizing and externalizing symptoms). The BPI has yielded good psychometric properties (e.g., Perren, Stadelmann, Lüdin, von Wyl, \& von Klitzing, 2008; Ringoot et al., 2013). Internalizing and externalizing symptom scales of the BPI showed acceptable internal consistency with Cronbach $\alpha=0.71$ and 0.79 , respectively.

Externalizing symptoms. Mothers and fathers completed the subscales conduct problems $(\alpha=0.62-0.63)$, hyperactivity $(\alpha=0.79-0.83)$, and peer problems $(\alpha=0.61-0.66)$ of the SDQ (Goodman, 1997). The mothers' and fathers' reports were significantly correlated $(r=.47-.65$, all $p s<.001)$. If both were available $(83.33 \%)$, mother and father reports were averaged ("parents"). Based on normative cutoffs, conduct problems and peer problems scores below 4, and hyperactivity scores below 6 , were categorized as "normal," scores of $4 / 6$, respectively, as "borderline," and scores of 5/7 and above as "abnormal" (Woerner et al., 2004).

Social competences. School teachers completed the 20item Self- and Other-Oriented Social Competences Questionnaire (SOCOMP; Perren, 2007). Items are rated between 0 (not true) and 2 (certainly true) and refer to diverse social behaviors of the child over the last 6 months. The SOCOMP contains two subscales: self-oriented social skills (assertivesociable behavior) and other-oriented skills (prosocial-cooperative behavior). Each subscale is composed of 10 items. Both subscales yielded good internal consistency (self-oriented: $\alpha=0.86$; other-oriented: $\alpha=0.84$ ).

Mental health care use. Mothers indicated whether or not their child had ever received a psychological intervention (yes $=1 /$ no $=0)$.

\section{Statistical analysis}

The first aim of the statistical analyses was to identify distinct developmental trajectories of internalizing symptoms from age 3 to age 9. To estimate latent trajectories, data were restructured into half-year intervals across all ages. Table 3 displays the age structure of the sample. Based on these data, we estimated latent trajectories of internalizing symptoms employing growth mixture models in Mplus version $7.2(\mathrm{Mu}-$ thén \& Muthén, 1998-2012), using full information maximum likelihood and the Yuan-Bentler scaled chi-square adjustment to improve robustness to both missing data and nonnormality. A series of increasingly complex models were run in three steps. First, to determine the overall shape of change over time, we estimated general growth models (one-class models) with the intercept centered at age 4 
Table 3. Age structure of the sample $(N=325)$ participating at one to four waves of data collection during the ages 3 to 9

\begin{tabular}{lrcc}
\hline \hline Age interval & $n$ & $M_{\text {age }}$ & $S D_{\text {age }}$ \\
\hline $3.0-3.49$ & 27 & 3.34 & 0.08 \\
$3.5-3.99$ & 58 & 3.85 & 0.13 \\
$4.0-4.49$ & 155 & 4.24 & 0.15 \\
$4.5-4.99$ & 158 & 4.72 & 0.15 \\
$5.0-5.49$ & 103 & 5.23 & 0.16 \\
$5.5-5.99$ & 78 & 5.71 & 0.13 \\
$6.0-6.49$ & 17 & 6.22 & 0.15 \\
$6.5-6.99$ & 4 & 6.87 & 0.13 \\
$7.0-7.49$ & 185 & 7.33 & 0.12 \\
$7.5-7.99$ & 71 & 7.67 & 0.14 \\
$8.0-8.49$ & 144 & 8.33 & 0.12 \\
$8.5-8.99$ & 99 & 8.71 & 0.16 \\
\hline \hline
\end{tabular}

(mean age at Wave 1). Different model specifications were considered, comparing models with linear change, quadratic change, and accelerated change (including linear and quadratic change components). The best fitting model was selected to represent the basic developmental course of internalizing symptoms over time. In the second step, we increased the number of latent trajectory classes estimated from this best fitting one-class model in order to determine the final number of latent trajectory classes. In each model, means of growth parameters were allowed to differ across trajectory classes, but variances and residual variances were restricted to be equal. In the third step, after selecting the number of trajectory classes, we reassessed whether lifting these restrictions further improved the model fit to ensure that our final model best captures the latent trajectory classes of internalizing symptoms from age 3 to 9 .

Several fit indices were used to compare models, including descriptive measures of overall model fit, such as the Akaike information criterion, the Bayesian information criterion, and the sample-size adjusted Bayesian information criterion, where lower values indicate better fit. We also employed the Vuong-Lo-Mendell-Rubin likelihood ratio test as a means to evaluate whether a particular model better fits the data than a more parsimonious model with fewer classes (Nylund, Asparouhov, \& Muthén, 2007). In addition, we employed entropy, an assessment of how well individuals are categorized within classes and how distinct the classes are, to assess model fit. Entropy ranges from 0 to 1, with higher values indicating greater class separation (Lubke \& Muthén, 2007).

After identifying the distinct trajectory classes, we conducted chi-squared tests, multivariate analyses of variance (MANOVAs) and analyses of variance (ANOVAs) in IBM SPSS Statistics (Version 22) to determine whether gender, sociodemographic variables, risk, maintenance as well as outcome variables were differentially associated with membership of trajectory classes. If expected frequencies in the chisquared test were lower than 5, we used Fisher's exact test. In the event that Levene's $F$ test revealed that homogeneity of variance was not met, we additionally used Welch's $F$ test to verify significance. We conducted post hoc tests to determine which pairs of groups differed significantly. We employed the Games-Howell procedure to account for violation of homogeneity of variance and unequal sample sizes (Field, 2013). Finally, using Mplus with Monte Carlo integration and full information maximum likelihood, we conducted a multinomial logistic regression analysis to examine the relative contribution of several predictors (i.e., in the presence of others) on trajectories of internalizing symptoms.

\section{Results}

\section{Trajectories of internalizing symptoms}

Change in internalizing symptoms over time: General growth model. As a first step the basic developmental course of internalizing symptoms over time was determined. A linear growth curve model, root mean square error of approximation $=$ 0.025 , confirmatory fit index $=0.959, \chi^{2}(64)=77.16$, $p=.13$, fit the data comparably to a quadratic growth curve model, root mean square error of approximation $=0.022$, confirmatory fit index $=0.969, \chi^{2}(64)=74.14, p=.18$ (for the Akaike information criterion, the Bayesian information criterion, and the sample-size adjusted Bayesian information criterion, see Table 4). An accelerated change model with both linear and quadratic change components failed to converge, and was thus excluded from further analyses. The mean intercept (mean level of internalizing symptoms at age 4) was 2.82 points for the linear change model ( 2.83 for quadratic model; both differed significantly from zero, $p<.001)$. The means of the change components were not significantly different from zero in both models (linear: $-0.04, p=.30$ and quadratic: $-0.01, p=.22$ ), explaining the high similarity of model fit in both models (see Table 4). Thus, the average trajectory of internalizing symptoms started at low to moderate levels and remained stable between ages 3 and 9 . However, there was significant interindividual variance in both intercepts $(3.21, p<$ .001 , and 3.04, $p<.001$, for the linear and quadratic model, respectively) and change parameters $(0.17, p<.001$, and $0.01, p<.001$, respectively). This indicates that there were some children with lower or higher levels of internalizing symptoms at age 4 , and children whose internalizing symptoms changed over time. Derivation of different trajectory classes in internalizing symptoms between ages 3 and 9 was therefore justified.

Differences in level and change in internalizing symptoms over time: Latent trajectory classes. Next, we computed both linear and quadratic trajectories, as model fits of the one-class models were comparable, in the growth mixture models with higher numbers of latent trajectory classes. The fit statistics indicated that the four-class solution with two linear and two quadratic change trajectories offers the best model fit (see Table 4). This model was also superior to models that lifted the restrictions of equal group variances. 
Table 4. Model fit statistics for growth mixture models, with only the best fitting models reported for the multiclass models

\begin{tabular}{|c|c|c|c|c|c|}
\hline Model & AIC & $\mathrm{BIC}$ & $\mathrm{aBIC}$ & VLMR-LRT $(p)$ & Entropy \\
\hline \multicolumn{6}{|l|}{1 class } \\
\hline linear change & 4546.63 & 4610.96 & 4557.03 & - & - \\
\hline quadratic change & 4543.61 & 4607.94 & 4554.01 & - & - \\
\hline \multicolumn{6}{|l|}{2 classes } \\
\hline 1 linear +1 quadratic & 4510.63 & 4590.09 & 4523.48 & .12 & .56 \\
\hline \multicolumn{6}{|l|}{3 classes } \\
\hline 1 linear +2 quadratic & 4498.80 & 4593.39 & 4514.10 & .54 & .66 \\
\hline all quadratic ${ }^{\mathrm{a}}$ & 4497.77 & 4588.58 & 4512.46 & .09 & .48 \\
\hline \multicolumn{6}{|l|}{4 classes } \\
\hline 2 linear +2 quadratic & 4490.66 & 4600.39 & 4508.40 & .05 & .66 \\
\hline all quadratic ${ }^{\mathrm{a}}$ & 4489.84 & 4595.79 & 4506.97 & .15 & .60 \\
\hline \multicolumn{6}{|l|}{5 classes } \\
\hline 4 linear +1 quadratic $^{b}$ & 4495.98 & 4620.85 & 4516.18 & .34 & .63 \\
\hline
\end{tabular}

Note: AIC, Akaike information criterion; BIC, Bayesian information criterion; aBIC, sample-size adjusted BIC. For AIC, BIC, and aBIC lower values indicate better fitting models. VLMR-LRT, Vuong-Lo-Mendell-Rubin likelihood ratio test, where significant $p$ values indicate that a particular model fits better than a model with one fewer class. Entropy assesses how well individuals were categorized within groups, with higher values indicating greater class separation; for each number of classes, the full range of possible linear and quadratic models was conducted. Here we report only those that converged with no problems, or only minimal ones (which is indicative of better fit to the data).

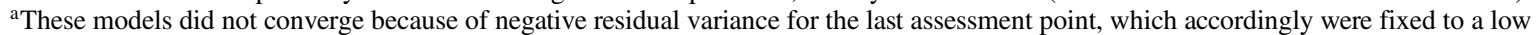
value of .001. ${ }^{\mathrm{b}}$ This model included two Heywood cases with the correlations of intercept and slope in class 1 and 2 being greater than 1.

Figure 1 illustrates the four estimated trajectories of internalizing symptoms between ages 3 and 9 , and parameter estimates are provided in Table 5 . There were 93 children (28.6\%; 51 males, 42 females) in a "stable low" class with a posterior probability (indicating how well children fit into this group, ranging from zero to 1 ) of .83 . Children in this trajectory had low levels of internalizing symptoms at age 4 $(b=1.01, p<.001)$ that did not change as they grew older $(b=-0.09, p=.19)$. There were 47 children $(14.5 \% ; 26$ males, 21 females) in a "rising low to moderate" class with a posterior

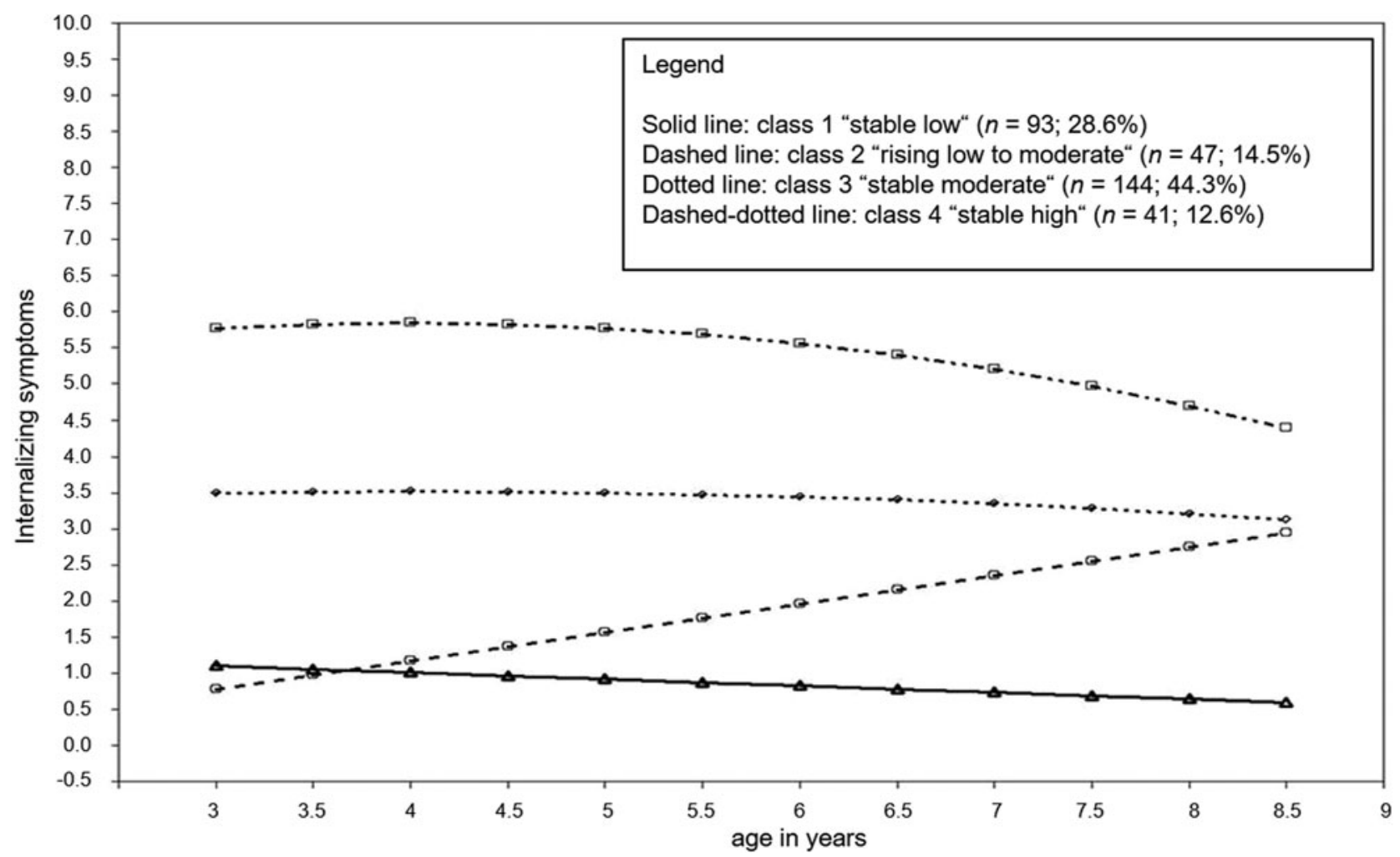

Figure 1. Estimated trajectories of internalizing symptoms from age 3 to age 9. 
Table 5. Results from the final four-class growth mixture model with two linear and two quadratic growth curves

\begin{tabular}{|c|c|c|c|c|}
\hline & $\begin{array}{l}\text { Class } 1 \\
\text { "stable low" }\end{array}$ & $\begin{array}{l}\text { Class } 2 \text { "rising } \\
\text { low to moderate" }\end{array}$ & $\begin{array}{c}\text { Class } 3 \\
\text { "stable moderate" }\end{array}$ & $\begin{array}{l}\text { Class } 4 \\
\text { "stable high" }\end{array}$ \\
\hline Type of change & linear & linear & quadratic & quadratic \\
\hline Group size, $n(\%)$ & $93(28.6 \%)$ & $47(14.5 \%)$ & $144(44.3 \%)$ & $41(12.6 \%)$ \\
\hline \multicolumn{5}{|l|}{ Intercept: Mean level of internalizing } \\
\hline symptoms at age 4 & $1.01 * * *$ & $1.17 * * *$ & $3.51 * * *$ & $5.85 * * *$ \\
\hline$(S E)$ & $(0.21)$ & $(0.25)$ & $(0.40)$ & $(0.79)$ \\
\hline Intercept variance & 0.351 & 0.351 & 0.351 & 0.351 \\
\hline$(S E)$ & $(0.31)$ & $(0.31)$ & $(0.31)$ & $(0.31)$ \\
\hline \multicolumn{5}{|c|}{ Slope: Mean rate of change in internalizing } \\
\hline symptoms over time & -0.09 & $0.40 * * *$ & -0.02 & -0.07 \\
\hline$(S E)$ & $(0.07)$ & $(0.12)$ & $(0.03)$ & $(0.07)$ \\
\hline \multirow{2}{*}{$\begin{array}{l}\text { Slope variance } \\
\quad(S E)\end{array}$} & $0.02 * * *$ & $0.02 * * *$ & $0.02 * * *$ & $0.02 * * *$ \\
\hline & $(0.003)$ & $(0.003)$ & $(0.003)$ & $(0.003)$ \\
\hline \multirow{2}{*}{$\begin{array}{l}\text { Correlation of intercept and slope } \\
(S E)\end{array}$} & $-.91 * * *$ & .00 & $-.71 * * *$ & -.67 \\
\hline & $(0.28)$ & $(0.93)$ & $(0.22)$ & $(0.46)$ \\
\hline
\end{tabular}

Note: $* * * p<.001$.

probability of .73 (hereafter referred to as "rising"). Children in this trajectory had low initial levels of internalizing symptoms $(b=1.71, p<.001)$ that increased to a medium level as they grew older $(b=0.40, p<.001)$. The largest group of children ( $n=144,44.3 \%$; 70 males, 74 females) belonged to a third "stable moderate" class with a posterior probability of .80. Children in this trajectory showed a medium level of internalizing symptoms at age 4 (i.e., just below the "borderline" cutoff of the SDQ; $b=3.52, p<.001)$ that remained stable over time $(b=-0.02, p=.47)$. Finally, 41 children $(12.6 \%$; 20 males, 21 females) belonged to a "stable high" class with a posterior probability of .85 . Children in this trajectory had elevated internalizing symptoms at age $4(b=5.85, p<.001)$ that did not change as they grew older $(b=-0.07, p=.27)$. These children on average manifested internalizing symptoms in an "abnormal" range (SDQ cutoff $=5$ ).

\section{Characteristics of trajectory classes}

Sociodemographics. There were no differences between classes in terms of gender with $42(45.2 \%)$ females in the "stable low," 21 (44.7\%) in the "rising," 74 (51.4\%) in the "stable moderate," and 21 (51.2\%) in the "stable high" classes, $\chi^{2}(3, N=325)=1.29, p=.731$. Classes were also comparable in terms of other sociodemographic characteristics: parental education, household income, and domestic situation (all $\mathrm{ps}>$.138).

Differential attrition. Classes differed significantly in regard to dropout rates until Wave 4: more children in the "stable high" ( $n=14 ; 34.1 \%)$ and "stable moderate" $(n=43$; $29.9 \%$ ) classes dropped out than in the "rising" ( $n=1$; $2.1 \%)$ and "stable low" $(n=18 ; 19.4 \%)$ classes, $\chi^{2}(3, N$ $=325)=18.72, p<.001$. The parents of 10 children in the "stable high" class rationalized their discontinuation with a high time burden (e.g., because of many medical visits of the child). In 4 cases there were other reasons (e.g., no contact data available after the family had moved).

Father and preschool teacher ratings of internalizing symptoms. We examined internalizing symptoms rated by fathers and preschool teachers at preschool age to assess concordance between informants, as well as presence/absence of anxiety disorder/depression assessed with clinical interviews to inform clinical relevance.

ANOVAs with internalizing symptoms rated by fathers and preschool teachers at preschool age as dependent variables and trajectory class as independent variable revealed significant differences between classes, with moderate to high effect sizes, father report: $F(3,242)=30.12$, $p<.001, \eta_{\mathrm{P}}^{2}=0.272$; preschool teacher report: $F(3,260)=$ $7.15, p<.001, \eta_{\mathrm{P}}^{2}=0.076$. Post hoc tests revealed differences between father and teacher ratings of internalizing symptoms of children in different trajectories. According to fathers, children belonging to the "stable low" ( $M=0.96$, $S D=1.06)$ and "rising" classes $(M=1.62, S D=1.40)$ showed the lowest and comparable levels of internalizing symptoms ( $p=.066$ ); children belonging to the "stable moderate" class $(M=2.61, S D=1.86)$ showed intermediate levels (significantly different from classes "stable low" and "rising"; $p<.010)$; and children belonging to the "stable high" class $(M=4.21, S D=2.57)$ showed the highest level of symptoms (significantly different from all other classes; $p<.010)$. According to preschool teachers, children belonging to the "stable low" $(M=1.15, S D=1.77)$ and "rising" classes $(M=1.16, S D=1.67)$ showed the lowest levels of internalizing symptoms $(p=.999)$; children belonging to the "stable moderate" class $(M=1.82, S D=1.94)$ were comparable to all other classes $(p>.066)$; and children of the "stable high" class $(M=2.83, S D=2.31)$ showed the 
Table 6. Presencelabsence of anxiety disorder/depression at preschool age (Wave 2; $M_{\text {Age }}=5 ; 2$ ) in different trajectory classes

\begin{tabular}{llcccc}
\hline \hline & \multicolumn{3}{c}{ Trajectory classes } \\
\cline { 3 - 6 } & & $\begin{array}{c}\text { Class 1 } \\
\text { "stable low" }\end{array}$ & $\begin{array}{c}\text { Class 2 "rising } \\
\text { low to moderate" }\end{array}$ & $\begin{array}{c}\text { Class 3 } \\
\text { "stable moderate" }\end{array}$ & $\begin{array}{c}\text { Class 4 } \\
\text { "stable high" }\end{array}$ \\
\hline No disorder & $n(\%)$ & $37(54.4)$ & $21(52.5)$ & $34(28.1)$ & $2(5.4)$ \\
Pure anxiety disorder & $n(\%)$ & $22(32.4)$ & $14(35.0)$ & $48(39.7)$ & $94(35.3)$ \\
Depression & $n(\%)$ & $9(13.2)$ & $5(12.5)$ & $39(32.2)$ & $93(24.3)$ \\
Total & $n$ & 68 & 40 & 121 & $79(29.0)$ \\
\hline \hline
\end{tabular}

Note: $n=59(18.2 \%)$ missing.

highest level of symptoms (significantly different from classes "stable low" and "rising"; $p<.010$ ).

Anxiety disorder/depression at preschool age. Overall, $n=94$ (35.3\%) out of $n=266$ ( $n=59 ; 18.2 \%$ missing) children received no diagnosis, $n=93(35.0 \%)$ were diagnosed with a pure anxiety disorder, and $n=79(29.7 \%)$ were diagnosed with depression (with and without comorbid anxiety disorder) at preschool age (Wave 2, $M_{\text {Age }}=5 ; 2$ years). We found significant differences in the presence/absence of anxiety disorders/depression between classes, $\chi^{2}(6, N=266)=$ $54.56, p<.001$. The majority of children in the "stable low" $(n=37 ; 54.4 \%)^{1}$ and "rising" classes $(n=21 ; 52.5 \%)$ received no diagnosis (consistent with the "rising" pattern of low initial internalizing symptoms at preschool age) while children in the "stable moderate" class predominantly received a pure anxiety disorder diagnosis $(n=48 ; 39.7 \%)$ and children in the "stable high" class predominantly received a depression diagnosis $(n=$ 26; 70.3\%); see Table 6.

\section{Risk and maintenance factors}

The second aim of our study was to identify risk factors for unfavorable courses of internalizing symptoms. To test our hypotheses that a higher proportion of children in high-risk trajectories would have been exposed to stressful life events and early maltreatment prior to age 3 , we computed chisquared tests. To test our hypotheses that children in highrisk trajectories would have mothers with more mental health problems and exhibit more cortisol dysregulation at preschool age, we conducted a set of ANOVAs.

Stressful life events. A total of $n=62$ (25.3\%) out of $n=245$ ( $n=80,24.6 \%$ missing) children had experienced life events relating to loss/separation, $n=80(32.7 \%)$ life events relating to transitions, and $n=65(26.5 \%)$ life events relating to threat to the child's physical health before the age of 3 . Trajectory classes differed in terms of life events relating to loss/separation: more children in the "stable high" class $(n=15 ; 55.6 \%)$

1. Here and in the following chi-squared tests, valid percentages are presented. had experienced a loss of/separation from a significant person before the age of 3 than in the "stable low" $(n=12 ; 16.7 \%)$, the "rising" $(n=14 ; 30.4 \%)$, and the "stable moderate" $(n=21$; $21.0 \%)$ classes, $\chi^{2}(3, N=245)=17.54, p=.001$. By contrast, trajectory classes were comparable in terms of the number of children exposed to life events of transitions in the child's environment, $\chi^{2}(3, N=245)=3.40, p=.338$, or threat to the child's physical health, $\chi^{2}(3, N=245)=2.81, p=$ .425 , before the age of 3 .

Maltreatment classification. Overall, $n=32$ (13.4\%) out of $n=239(n=86,26.5 \%$ missing $)$ children had experienced maltreatment before the age of 3 . Trajectory classes differed in terms of maltreatment experiences: more children in the "stable high" class $(n=6 ; 24.0 \%)$ had experienced maltreatment before the age of 3 than in the "stable low" $(n=3 ; 4.4 \%)$, the "rising" $(n=4 ; 9.3 \%)$, and the "stable moderate" $(n=19 ; 18.4 \%)$ classes, $\chi^{2}(3, N=239)=10.46, p=.012$ (Fisher's exact test).

Maternal mental health problems. The MANOVA revealed significant differences between trajectory classes in maternal depressive symptoms, somatization, and stress, $F(9,837)=$ $6.48, p<.001, \eta_{\mathrm{P}}^{2}=0.065$. In the ANOVAs, we found significant differences in all subscales with high effect sizes $\left(\eta_{\mathrm{p}}^{2}\right.$ $=0.098-0.180$; see Table 7). In accordance with our hypothesis, post hoc tests revealed that mothers of children in the "stable low" class reported the lowest levels of depressive symptoms and somatization, while mothers of children in the "stable moderate" class reported intermediate levels and mothers of children in the "stable high" class reported the highest levels. Mothers of children in the "rising" class reported symptom levels that were comparable to the "stable low" and "stable moderate" classes. Further, mothers of children in the "stable high" class reported higher stress levels than those of the three other classes, which described comparable stress levels (for $M, F, p$, and $\eta_{\mathrm{p}}^{2}$; see Table 7).

Children's temperament. The MANOVA revealed significant differences between trajectory classes in child temperament dimensions surgency, negative affectivity, and effortful control, $F(9,837)=9.04, p<.001, \eta_{\mathrm{P}}^{2}=0.089$. In the ANOVAs, we found significant differences in surgency $\left(\eta_{p}^{2}\right.$ 
Table 7. Differences between trajectory classes in child temperament and maternal mental health problems at preschool age (Wave $2 ; M_{\text {Age }}=5 ; 2$ )

\begin{tabular}{|c|c|c|c|c|c|c|}
\hline & \multirow{2}{*}{$\begin{array}{c}\text { Class } 1 \\
\text { "stable low" } \\
M(S D)\end{array}$} & \multirow{2}{*}{$\begin{array}{c}\text { Class } 2 \text { "rising } \\
\text { low to moderate" } \\
M(S D)\end{array}$} & \multirow{2}{*}{$\begin{array}{c}\text { Class } 3 \\
\text { "stable moderate" } \\
M(S D)\end{array}$} & \multirow{2}{*}{$\begin{array}{c}\text { Class } 4 \\
\text { "stable high" } \\
M(S D)\end{array}$} & \multicolumn{2}{|c|}{ Univariate tests } \\
\hline & & & & & $F$ & $\eta_{\mathrm{P}}^{2}$ \\
\hline \multicolumn{7}{|l|}{ Maternal mental health problems } \\
\hline PHQ depressive symptoms & $3.15(3.13)^{\mathrm{a}}$ & $4.18(3.90)^{\mathrm{a}, \mathrm{b}}$ & $4.66(3.84)^{b}$ & $8.15(5.16)^{\mathrm{c}}$ & $14.74 * * * 1$ & .137 \\
\hline PHQ somatization & $4.11(2.92)^{\mathrm{a}}$ & $5.03(3.70)^{\mathrm{a}, \mathrm{b}}$ & $5.88(3.57)^{b}$ & $9.46(4.45)^{\mathrm{c}}$ & $20.41 * * * 1$ & .180 \\
\hline PHQ stress & $3.58(3.13)^{\mathrm{a}}$ & $3.70(2.32)^{\mathrm{a}}$ & $4.77(3.45)^{\mathrm{a}}$ & $6.93(3.94)^{b}$ & $10.16 * * * 1$ & .098 \\
\hline \multicolumn{7}{|l|}{ Child temperament } \\
\hline CBQ-VSF surgency & $3.71(0.77)^{\mathrm{a}}$ & $3.58(0.73)^{\mathrm{a}, \mathrm{b}}$ & $3.44(0.76)^{\mathrm{a}, \mathrm{b}}$ & $3.21(0.84)^{\mathrm{b}, \mathrm{c}}$ & $4.09 * *$ & .042 \\
\hline CBQ-VSF negative affectivity & $2.68(0.84)^{\mathrm{a}}$ & $2.83(0.94)^{\mathrm{a}}$ & $3.39(0.85)^{\mathrm{b}}$ & $4.02(0.92)^{\mathrm{c}}$ & $25.03 * * *$ & .212 \\
\hline CBQ-VSF effortful control & $4.79(0.70)^{\mathrm{a}}$ & $4.90(0.62)^{\mathrm{a}}$ & $4.74(0.67)^{\mathrm{a}}$ & $4.55(0.77)^{\mathrm{a}}$ & 1.91 & .020 \\
\hline
\end{tabular}

Note: Analyses of variance, two-tailed, $d f=3,277-278 .{ }^{\mathrm{a}, \mathrm{b}, \mathrm{c}}$ Different letters indicate significant group differences found in post hoc analyses (Games-Howell). PHQ, Patient Health Questionnaire. CBQ-VSF, Children's Behavior Questionnaire-Very Short Form. $* * p<.01, * * * p<.001 .{ }^{1}$ If homogeneity of variance assumption was not met, we additionally used Welch's $F$ test to verify significance, revealing the same results.

$=0.042)$ and negative affectivity $\left(\eta_{\mathrm{p}}^{2}=0.212\right)$, whereas classes did not differ in effortful control (for details, see Table 7). Post hoc tests revealed that children in the "stable low" class showed higher levels of surgency than children of all other classes. Moreover, children in the "stable low" and "rising" classes showed the lowest levels of negative affectivity, children in the "stable moderate" class showed intermediate levels, and children in the "stable high" class showed the highest levels (for $M, F, p$, and $\eta_{\mathrm{p}}^{2}$; see Table 7).

Neurobiological stress regulation (cortisol reactivity). An ANOVA with trajectory class and gender as independent variables and area under the curve with respect to ground cortisol (log-transformed) as a dependent variable revealed significant differences in cortisol levels between classes, $F$ $(3,202)=3.06, p=.029, \eta_{\mathrm{P}}^{2}=0.043$, but no gender effect, $F(1,202)=0.38, p=.537, \eta_{\mathrm{P}}^{2}=0.002$. Post hoc tests (Bonferroni) revealed that cortisol levels in the "stable high" class $(M=2.33, S D=0.18)$ were significantly lower than in the "rising" class $(M=2.47, S D=0.18 ; p=.028)$ while cortisol levels of all other classes were comparable ("stable moderate" class: $M=2.44, S D=0.17$; "stable low" class: $M=2.42, S D$ $=0.22$; all $p \mathrm{~s}>.05$ ); see Figure 2 .

Predictors for distinguishing between trajectory classes. Using Mplus with Monte Carlo integration and full information maximum likelihood, we conducted a multinomial logistic regression analysis to examine the relative contribution of predictors (in the presence of others) in differentiating between each the "rising," "stable moderate," and "stable high" classes versus the "stable low" class (reference group). We included those variables as predictors that significantly differentiated between classes in previous analyses: life events relating to loss/separation, maltreatment experiences, maternal mental health problems (sum of depression, somatization, and stress), child temperament dimensions surgency and negative affectivity, and cortisol reactivity. Moreover, we included child gender as control variable. Table 8 gives the individual parameter estimates.

Predictors for distinguishing between the "rising" and the "stable low" trajectory classes. Life events relating to loss/ separation before the age of 3 were a significant predictor in distinguishing the "rising" from the "stable low" classes. As the loss/separation parameter changes from 0 (not present) to 1 (present), the change in the odds is $0.39(p=.048)$, and thus the odds of belonging to the "rising" than to the "stable low" class is $1.00: 0.39=2.56$ times higher when a life event relating to loss/separation was present than when it was not.

Predictors for distinguishing between the "stable moderate" and the "stable low" trajectory classes. Maternal mental health problems, child temperament surgency, and negative affectivity significantly differentiated the "stable moderate" from the "stable low" symptoms class. Higher maternal mental health problems (odds ratio $[O R]=1.06, p=.010$ ), lower surgency $(O R=0.51, p=.003)$, and higher negative affectivity $(O R=2.31, p<.001)$ were associated with increased

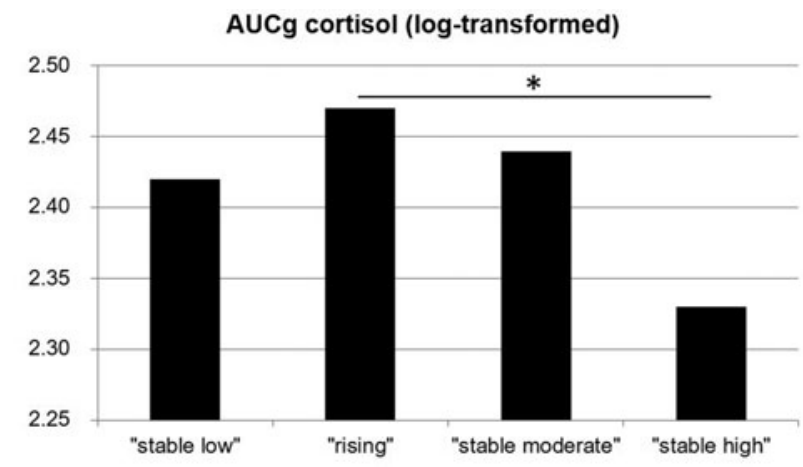

Figure 2. Cortisol reactivity (area under the curve with respect to ground cortisol, log-transformed) in different trajectory classes. Note: $* p<.05$. 
Table 8. Parameter estimates of multinomial logistic regression analysis

\begin{tabular}{|c|c|c|c|c|}
\hline & \multirow[b]{2}{*}{$B(S E)$} & \multicolumn{3}{|c|}{$95 \%$ CI for odds ratio } \\
\hline & & Lower & $\begin{array}{c}\text { Odds } \\
\text { ratio }\end{array}$ & Upper \\
\hline \multicolumn{5}{|l|}{ "Rising" class vs. "stable low" class } \\
\hline Intercept & $-2.34(3.21)$ & & & \\
\hline PHQ maternal mental health problems & $0.04(0.03)$ & 0.99 & 1.04 & 1.10 \\
\hline CBQ-VSF surgency & $-0.38(0.28)$ & 0.39 & 0.68 & 1.19 \\
\hline CBQ-VSF negative affectivity & $0.13(0.24)$ & 0.71 & 1.14 & 1.83 \\
\hline Cortisol reactivity & $1.35(1.21)$ & 0.36 & 3.84 & 41.29 \\
\hline \multicolumn{5}{|l|}{ Gender } \\
\hline$(0=$ female $)$ & $-0.07(0.38)$ & 0.44 & 0.93 & 1.94 \\
\hline \multicolumn{4}{|l|}{ Life events loss/separation } & 0.99 \\
\hline Maltreatment experiences $(0=$ not present $)$ & $-0.37(0.82)$ & 0.14 & 0.69 & 3.45 \\
\hline \multicolumn{5}{|l|}{ "Stable moderate" class vs. "stable low" class } \\
\hline Intercept & $0.02(2.65)$ & & & \\
\hline PHQ maternal mental health problems & $0.06(0.02)^{*}$ & 1.01 & 1.06 & 1.10 \\
\hline CBQ-VSF surgency & $-0.68(0.23)^{* *}$ & 0.32 & 0.51 & 0.79 \\
\hline CBQ-VSF negative affectivity & $0.85(0.20)^{* * *}$ & 1.58 & 2.33 & 3.43 \\
\hline Cortisol reactivity & $0.31(1.01)$ & 0.19 & 1.36 & 9.85 \\
\hline \multicolumn{5}{|l|}{ Gender } \\
\hline$(0=$ female $)$ & $0.09(0.31)$ & 0.60 & 1.09 & 1.99 \\
\hline \multicolumn{5}{|l|}{ Life events loss/separation } \\
\hline$(0=$ not present $)$ & $-0.42(0.46)$ & 0.27 & 0.66 & 1.63 \\
\hline Maltreatment experiences $(0=$ not present $)$ & $-0.99(0.71)$ & 0.09 & 0.37 & 1.50 \\
\hline \multicolumn{5}{|l|}{ "Stable high" class vs. "stable low" class } \\
\hline Intercept & $5.80(4.50)$ & & & \\
\hline PHQ maternal mental health problems & $0.16(0.03) * * *$ & 1.10 & 1.17 & 1.24 \\
\hline CBQ-VSF surgency & $-1.48(0.37)^{* * *}$ & 0.11 & 0.23 & 0.47 \\
\hline CBQ-VSF negative affectivity & $1.62(0.34)^{* * *}$ & 2.59 & 5.04 & 9.81 \\
\hline Cortisol reactivity & $-3.49(1.82)^{+}$ & 0.00 & 0.03 & 1.07 \\
\hline \multicolumn{5}{|l|}{ Gender } \\
\hline$(0=$ female $)$ & $-0.19(0.53)$ & 0.29 & 0.83 & 2.32 \\
\hline \multicolumn{5}{|l|}{ Life events loss/separation } \\
\hline$(0=$ not present $)$ & $-2.77(0.74) * * *$ & 0.02 & 0.06 & 0.27 \\
\hline Maltreatment experiences $(0=$ not present $)$ & $0.85(1.12)$ & 0.26 & 2.34 & 21.16 \\
\hline
\end{tabular}

Note: PHQ, Patient Health Questionnaire. CBQ-VSF, Children's Behavior Questionnaire—Very Short Form. $+p<.10,{ }^{*} p<.05, * * p$ $<.01, * * * p<.001$.

probability of belonging to the "stable moderate" than the "stable low" class.

Predictors for distinguishing between the "stable high" and the "stable low" trajectory classes. Maternal mental health problems, child temperament surgency, negative affectivity, and life events relating to loss/separation before the age of 3 were significant predictors in distinguishing the "stable high" from the "stable low" class, while cortisol reactivity showed a tendency toward significance and the presence of maltreatment experiences before the age of 3 was not significant. Higher maternal mental health problems $(O R=1.17$, $p<.001)$, lower surgency $(O R=0.23, p<.001)$, higher negative affectivity $(O R=5.04, p<.001)$, and lower cortisol reactivity $(O R=0.03$, trend, $p=.055)$ were associated with increased probability of belonging to the "stable high" than the "stable low" class. Furthermore, the experience of life events relating to loss/separation before the age of 3 was a significant predictor: as the loss/separation parameter changes from 0 (not present) to 1 (present), the change in the odds is $0.06(p<.001)$, and thus the odds of belonging to the "stable high" than to the "stable low" class is $1.00: 0.06=$ 16.66 times higher when a life event relating to loss/separation was present than when it was not.

\section{Outcome at middle elementary school age}

The third aim of our study was to examine the outcome of children in distinct trajectory classes, that is, specific anxiety and depressive symptoms, social impairment, externalizing symptoms, and social competences, as well as anxiety disorders/depression and mental health care use at middle elementary school age (Wave 4) using reports of multiple informants (parents, teacher, and child). To test our hypotheses that chil- 
dren in high-risk trajectories would exhibit higher symptoms and social impairment and lower self-oriented social competences, we conducted a set of MANOVAs and ANOVAs followed by post hoc tests.

Symptoms and social competences. As expected, ANOVAs revealed significant differences between classes in SCARED total anxiety, CES-DC total depression, and SDQ total impact scores, externalizing symptoms (parent ratings) as well as SOCOMP self- and other-oriented social competences (teacher rating; for MANOVAs, $M, F, p$, and $\eta_{\mathrm{p}}^{2}$, see Table 9).

The ANOVAs on anxiety and depressive symptoms and social impairment revealed large effect sizes $\left(\eta_{\mathrm{p}}^{2}=0.151-\right.$ 0.260). Post hoc tests showed that the "stable low" class exhibited the lowest and the "stable high" class the highest levels of anxiety and depressive symptoms and social impairment while the "rising" and "stable moderate" classes were in between the two (comparable to each other, and partly to other classes, for details see Table 9). Of note, the average anxiety and depression scores of children in the "stable high" class fell only just below the cutoff for "clinical" anxiety symptoms $(M=$ $22.59, S D=9.89$; cutoff: SCARED total anxiety core $\geq 25$ ) and depression $(M=11.59, S D=5.66$; cutoff: CES-DC total depression score $\geq 15$ ), respectively.

Children's self-report of internalizing symptoms yielded a marginally significant difference between classes $(p=.052$, $\eta_{\mathrm{p}}^{2}=0.034$; no differences post hoc): children belonging to the "stable moderate" and "stable high" classes descriptively reported somewhat higher symptoms than children belonging to the "stable low" and "rising" classes, while child ratings of externalizing symptoms were comparable across classes (see Table 9).

We also found differences between classes regarding comorbid externalizing symptoms (parent ratings of the SDQ subscales conduct problems, hyperactivity, and peer problems) with medium effect sizes $\left(\eta_{\mathrm{p}}^{2}=0.072-0.090\right)$ : the "stable high" class (and regarding hyperactivity and peer problems the "stable moderate" class as well) exhibited higher levels of externalizing symptoms than the "stable low" class, while the "rising" class showed symptom levels comparable to all other classes (for details, see Table 9). It is noteworthy, however, that children belonging to the "stable moderate" and "stable high" classes, on average, manifested externalizing symptoms below the borderline cutoff.

Table 9. Differences between trajectory classes in internalizing symptoms, impairment, externalizing symptoms and social competences rated by different informants at middle elementary school age (Wave $\left.4 ; M_{\text {Age }}=8 ; 5\right)$

\begin{tabular}{|c|c|c|c|c|c|c|}
\hline & \multirow{2}{*}{$\begin{array}{c}\text { Class } 1 \\
\text { "stable low" } \\
M(S D)\end{array}$} & \multirow{2}{*}{$\begin{array}{c}\text { Class } 2 \text { "rising } \\
\text { low to moderate" } \\
M(S D)\end{array}$} & \multirow{2}{*}{$\begin{array}{c}\text { Class } 3 \\
\text { "stable moderate" } \\
M(S D)\end{array}$} & \multirow{2}{*}{$\begin{array}{c}\text { Class } 4 \\
\text { "stable high" } \\
M(S D)\end{array}$} & \multicolumn{2}{|c|}{ Univariate tests } \\
\hline & & & & & $F$ & $\eta_{\mathrm{P}}^{2}$ \\
\hline \multicolumn{7}{|c|}{ Internalizing symptoms and social impairment } \\
\hline $\begin{array}{l}\text { SCARED total anxiety score } \\
\quad \text { (parents), } n=247\end{array}$ & $8.83(4.63)^{\mathrm{a}}$ & $14.52(6.62)^{\mathrm{b}}$ & $14.89(7.44)^{\mathrm{b}}$ & $22.59(9.89)^{\mathrm{c}}$ & $28.44 * * * 3$ & .260 \\
\hline $\begin{array}{l}\text { CES-DC total depression score } \\
\quad \text { (parents), } n=246\end{array}$ & $5.10(3.01)^{\mathrm{a}}$ & $7.63(5.52)^{b}$ & $8.53(5.09)^{\mathrm{b}, \mathrm{c}}$ & $11.56(5.66)^{\mathrm{c}}$ & $14.36 * * * 3$ & .151 \\
\hline $\begin{array}{l}\text { SDQ total impact score } \\
\quad \text { (parents), } n=244\end{array}$ & $0.02(0.18)^{\mathrm{a}}$ & $0.27(0.74)^{\mathrm{a}, \mathrm{b}}$ & $0.58(0.98)^{\mathrm{b}, \mathrm{c}}$ & $1.24(1.59)^{\mathrm{c}}$ & $14.21 * * * 3$ & .151 \\
\hline $\begin{array}{l}\text { BPI internalizing symptoms } \\
\quad \text { (child), } n=228\end{array}$ & $2.90(0.58)^{\mathrm{a}}$ & $2.98(0.47)^{\mathrm{a}}$ & $3.12(0.61)^{\mathrm{a}}$ & $3.18(0.52)^{\mathrm{a}}$ & $2.62^{+}$ & .034 \\
\hline \multicolumn{7}{|l|}{ Externalizing symptoms } \\
\hline $\begin{array}{l}\text { SDQ conduct problems } \\
\quad \text { (parents) }{ }^{1} n=246\end{array}$ & $0.95(0.96)^{\mathrm{a}}$ & $1.16(1.19)^{\mathrm{a}, \mathrm{b}}$ & $1.37(1.20)^{\mathrm{a}, \mathrm{b}}$ & $2.17(2.17)^{\mathrm{b}}$ & $6.30 * * * 3$ & .072 \\
\hline $\begin{array}{l}\text { SDQ hyperactivity (parents), } \\
\quad n=246 \\
\text { SDO peer problems (parents) }{ }^{1}\end{array}$ & $2.10(1.73)^{\mathrm{a}}$ & $2.82(1.74)^{\mathrm{a}, \mathrm{b}}$ & $3.46(2.31)^{\mathrm{b}}$ & $3.89(2.50)^{\mathrm{b}}$ & $7.96 * * * 3$ & .090 \\
\hline $\begin{array}{l}n=246 \\
\text { RPI }\end{array}$ & $0.57(0.82)^{\mathrm{a}}$ & $1.01(1.27)^{\mathrm{a}, \mathrm{b}}$ & $1.08(1.14)^{\mathrm{b}}$ & $1.83(2.00)^{\mathrm{b}}$ & $7.52 * * * 3$ & .085 \\
\hline (child), $n=228$ & $2.42(0.47)^{\mathrm{a}}$ & $2.37(0.41)^{\mathrm{a}}$ & $2.35(0.52)^{\mathrm{a}}$ & $2.58(0.82)^{\mathrm{a}}$ & 1.30 & .017 \\
\hline \multicolumn{7}{|l|}{ Social competencies } \\
\hline $\begin{array}{l}\text { SOCOMP self-oriented } \\
\quad \text { (teacher), }{ }^{2} n=210\end{array}$ & $1.55(0.32)^{\mathrm{a}}$ & $1.35(0.42)^{\mathrm{b}}$ & $1.36(0.44)^{\mathrm{b}}$ & $1.29(0.35)^{\mathrm{b}}$ & $4.33 * * 3$ & .059 \\
\hline $\begin{array}{l}\text { SOCOMP other-oriented } \\
\quad \text { (teacher) }{ }^{2} n=210\end{array}$ & $1.68(0.32)^{\mathrm{a}}$ & $1.55(0.35)^{\mathrm{a}}$ & $1.67(0.32)^{\mathrm{a}}$ & $1.47(0.35)^{\mathrm{a}}$ & $3.46^{*}$ & .048 \\
\hline
\end{tabular}

Note: Analyses of variance, two-tailed, $d f=3,206-243$. a,b,c Different letters indicate significant group differences found in post hoc analyses (Games-Howell). SCARED, Screen for Child Anxiety Related Emotional Disorders. CES-DC, Center for Epidemiologic Studies Depression Scale for Children. SDQ, Strengths and Difficulties Questionnaire. BPI, Berkeley Puppet Interview. SOCOMP, Self- and Other-Oriented Social Competences Questionnaire. * $p<.05, * * p<.01$, ${ }^{* * *} p<.001 ;{ }^{+} p<.10 .{ }^{1}$ Mulitivariate analysis of variance (SDQ conduct problems, hyperactivity, and peer problems): $F(9,726)=4.74 * * *, \eta_{\mathrm{P}}^{2}=.056$ ${ }^{2}$ Multivariate analysis of variance (SOCOMP self- and other-oriented): $F(6,412)=3.58^{* *}, \eta_{\mathrm{P}}^{2}=.050 .{ }^{3}$ If homogeneity of variance assumption was not met, we additionally used Welch's $F$ test to verify significance, revealing the same results. 
Analyses of the social competences (teacher rating) yielded differences between classes regarding social competences with small effect sizes $\left(\eta_{\mathrm{p}}^{2}=0.048-0.059\right)$ : children of the "stable low" class showed higher self-oriented social competences than children of all other classes (post hoc tests). Although there was a class effect with respect to other-oriented social competences, no differences between classes emerged post hoc (see Table 9).

Anxiety disorder/depression. To test our hypotheses that a higher proportion of children in high-risk trajectories would be diagnosed with an anxiety disorder/depression and had received psychological intervention at school age, we computed chi-squared tests.

Overall, $n=124$ (51.9\%) out of $n=239$ ( $n=86 ; 26.5 \%$ missing) children received no diagnosis, $n=77$ (32.2\%) were diagnosed with a pure anxiety disorder, and $n=38(15.9 \%)$ were diagnosed with depression (with and without anxiety disorder) at middle elementary school age (Wave $4, M_{\text {Age }}=$ $8 ; 5$ years). We found significant differences in the presence/absence of anxiety disorders/depression between classes, $\chi^{2}(6, N=239)=27.68, p<.001$ (Fisher's exact test). Most children in the "stable low" class $(n=53$; $72.6 \%$ ) received no diagnosis while children in the "rising" and "stable moderate" classes either received no diagnosis (class "rising": $n=20 ; 47.6 \%$; class "stable moderate": $n$ $=45 ; 46.4 \%$ ) or were diagnosed with a pure anxiety disorder (class "rising": $n=17 ; 40.5 \%$; class "stable moderate": $n=$ $34 ; 35.1 \%)$. Eleven $(40.7 \%)$ children in the "stable high" class had a pure anxiety disorder; $10(37.0 \%)$ suffered from depression-7 (25.9\%) with a depression diagnosis, 3 (11.1\%) with subthreshold dysthymia, 8 out of these 10 with a comorbid anxiety disorder-and $6(22.2 \%)$ had no disorder. For further details, see Table 10.

Mental health care use. Overall, $n=26$ (10.7\%) out of $n=$ 244 ( $n=81 ; 24.9 \%$ missing) children had ever received psychological intervention before middle elementary school age (Wave $4, M_{\text {Age }}=8 ; 5$ years). Trajectory classes differed in terms of mental health care use: more children in the "stable high" class $(n=9 ; 34.6 \%)$ had ever received psychological intervention than in the "stable low" $(n=4 ; 5.6 \%)$, the "ris- ing" ( $n=3 ; 6.5 \%)$, and the "stable moderate" $(n=10$; $10.0 \%$ ) classes, $\chi^{2}(3, N=244)=13.82, p=.002$ (Fisher's exact test).

\section{Discussion}

In this 5-year longitudinal study, we extended the burgeoning work on trajectories of internalizing symptoms from preschool to elementary school age by presenting some of the first research in this area in a high-risk sample (i.e., a community sample oversampled for internalizing symptoms). The high clinical risk associated with our stable high symptom trajectory was underscored by the high proportion of internalizing diagnoses $(>70 \%)$, as indexed by clinical interviews in preschool and in school age. Drawing on current multilevel approaches to internalizing problems (e.g., Hankin, 2012; Hastings et al., 2015; Mills et al., 2012), we investigated a comprehensive set of predictors/maintenance factors including neuroendocrine stress regulation.

We found four distinct trajectory classes of internalizing symptoms that differed significantly in terms of loss/separation and early maltreatment experiences, maternal mental health problems, child temperament, and cortisol reactivity. While controlling for one another, loss/separation, maternal mental health problems, temperament, and cortisol reactivity (trend) differentiated between the stable high and stable low internalizing symptom trajectories.

Moreover, class differences were apparent regarding the outcome at middle elementary school age, particularly the level of anxiety and depressive symptoms, social impairment, presence of anxiety disorders and depression, and mental health care use. As such, ours is one of the first studies in early childhood that covers a comprehensive set of psychosocial risk/maintenance factors that give rise to a chronic, clinically relevant, and neurobiologically distinct trajectory of internalizing symptoms.

\section{Trajectories of internalizing symptoms}

As distinct trajectories of internalizing symptoms have rarely been investigated in clinical-risk samples, we have begun to fill this research gap by identifying trajectory classes in a

Table 10. Presencelabsence of anxiety disorder/depression at middle elementary school age $\left(\right.$ Wave $\left.4 ; M_{A g e}=8 ; 5\right)$ in different trajectory classes

Trajectory classes

\begin{tabular}{|c|c|c|c|c|c|c|}
\hline & & & \multirow[b]{2}{*}{ Total } \\
\hline & & $\begin{array}{l}\text { Class } 1 \\
\text { "stable low" }\end{array}$ & $\begin{array}{l}\text { Class } 2 \text { "rising, } \\
\text { low to moderate" }\end{array}$ & $\begin{array}{c}\text { Class } 3 \text { "stable } \\
\text { moderate" }\end{array}$ & $\begin{array}{c}\text { Class } 4 \\
\text { "stable high" }\end{array}$ & \\
\hline No disorder & $n(\%)$ & $53(72.6)$ & $20(47.6)$ & $45(46.4)$ & $6(22.2)$ & $124(51.9)$ \\
\hline Pure anxiety disorder & $n(\%)$ & $15(20.5)$ & $17(40.5)$ & $34(35.1)$ & $11(40.7)$ & $77(32.2)$ \\
\hline Depression & $n(\%)$ & $5(6.8)$ & $5(11.9)$ & $18(18.6)$ & $10(37.0)$ & $38(15.9)$ \\
\hline Total & $n$ & 73 & 42 & 97 & 27 & 239 \\
\hline
\end{tabular}

Note: $n=86(26.5 \%)$ missing. 
community sample oversampled for internalizing symptoms. As hypothesized, we identified four distinct trajectories with stable low (28.6\%), moderate (44.3\%), and high symptoms $(12.6 \%)$, and a fourth class with low initial levels of internalizing symptoms, which increased to a moderate level (14.5\%). The four trajectory classes were comparable in sociodemographic characteristics, including socioeconomic characteristics and gender.

The three stable trajectories are consistent with the view that levels of early childhood problems are not merely transient but instead can persist, in keeping with previous findings (Bayer et al., 2012; Fanti \& Henrich, 2010; Weeks et al., 2014; Whalen et al., 2016). Consistent with earlier studies (Côté et al., 2009; Davis et al., 2015; Fanti \& Henrich, 2010; Nantel-Vivier et al., 2014), we also identified an increasing symptom trajectory. The pattern identified by our trajectories thus broadly resembles that detected in community samples, to some extent supporting continuity across these sample types. However, some differences emerged in terms of proportions of children following distinct trajectories: in our study, the highest proportion of children followed a stable moderate internalizing trajectory whereas other studies reported the highest proportion of children following low symptom trajectories (Nantel-Vivier et al., 2014; Sterba et al., 2007; Weeks et al., 2014; Whalen et al., 2016). This difference is likely attributable to our sampling strategy. Moreover, in line with several studies (Côté et al., 2009; Fanti \& Henrich, 2010; Sterba et al., 2007; Whalen et al., 2016), a considerable proportion of children in our study followed a high symptom trajectory (12.6\%). We extend this work by showing that children following the high symptom trajectory on average had internalizing symptoms in the "abnormal" range (Goodman, 1997) and have high odds of anxiety disorder and/or depression at preschool and school age.

In line with some previous studies (Bongers, Koot, van der Ende, \& Verhulst, 2003; Weeks et al., 2014) but not others (Shanahan, Calkins, Keane, Kelleher, \& Suffness, 2014; Sterba et al., 2007; Whalen et al., 2016), we did not find gender effects, that is, the same proportions of girls and boys followed the four distinct trajectory classes.

The trajectory classes were derived from maternal report. In addition, we examined internalizing symptoms at preschool age (i.e., early in the trajectory) rated by fathers and teachers. The four classes differed significantly in father and teacher reports, which corroborates convergent validity. Moreover, validity was also indicated by the pattern of absence/presence of preschool anxiety disorders and depression, assessed with clinical interviews: children belonging to the classes "stable low" and "rising" predominantly received no diagnosis (consistent with the fact that internalizing symptoms in the "rising" trajectory were still low at preschool age) while children in the class "stable moderate" were predominantly diagnosed with a pure anxiety disorder and children in the class "stable high" suffered from depression (with/ without comorbid anxiety) in the majority of cases. This underscores that children with a high symptom trajectory did have clinically relevant symptoms and disorders at an early age that showed high stability.

In a second step, we aimed at identifying risk and maintenance factors for developing such unfavorable courses of internalizing symptoms taking into account stressful life events, maltreatment, maternal mental health problems, and child temperament as well as the child's neurobiological stress regulation.

\section{Risk and maintenance factors for high internalizing trajectories}

In line with our hypothesis, stressful life events of loss or separation from a significant person prior to age 3 predicted the membership of the stable high symptom trajectory (in which many children suffered from depression). Over half of the children following a stable high symptom class had experienced loss/separation. Moreover, roughly one-third of children following the "rising" symptom trajectory were exposed to early loss/separation, a much higher proportion than in the other two classes. This is remarkable as these children still manifested low internalizing symptoms at preschool age and only manifested higher symptoms in the long term, thus indicating a potential role in the formation of high internalizing symptoms. In contrast, exposure to life events of transition in the child's environment or threat to the child's physical health and/or life were not associated with class membership. Loss of or separation from a significant person plays an important role in the etiology of depression (e.g., Zalsman, Brent, \& Weersing, 2006), potentially precipitating protest as well as, eventually, resignation and despair characterizing different internalizing trajectories (Mineka, Watson, \& Clark, 1998). Children in the first years of life may have a limited ability to cope with these kinds of stressful life events as they rely strongly on their caregiver's support in times of high arousal (Bowlby, 1980; Nolte, Guiney, Fonagy, Mayes, \& Luyten, 2011). In addition, studies on early institutional care have shown that exposure to deprivation associated with the loss of/separation from a significant person often has detrimental effects for the child's psychological development (for a review, see O'Connor, 2016; Zeanah, Gunnar, McCall, Kreppner, \& Fox, 2011).

In most of the studies so far, tallies of different kinds of stressful life events were used. Similar to the finding obtained in our study, these have been found to predict depression and anxiety in childhood and adolescence (e.g., Bufferd et al., 2014; Edwards et al., 2010; Kim et al., 2003; Luby et al., 2006) as well as membership of trajectory classes characterized by high internalizing symptoms (Weeks et al., 2014). Beyond this, our results support the notion that specifically early life events of loss/separation are risk factors for increasing or chronic internalizing symptoms (O'Connor, 2016), which, in turn, could be used to identify children at risk for an unfavorable development early on.

As another environmental risk factor, we investigated maltreatment experiences prior to the age of 3 , which, as hypoth- 
esized, showed higher prevalence in the classes with stable moderate and high internalizing symptoms. This is in line with earlier findings stating that especially maltreatment experiences in the first years of life are detrimental to children's healthy development and associated with mental health problems (e.g., Cicchetti \& Toth, 2015; Keiley et al., 2001; Manly et al., 2001; Robinson et al., 2009). So far, few studies investigated the predictive value of maltreatment for distinct internalizing trajectories, but two recent studies report comparable results (Lauterbach \& Armour, 2016; Whalen et al., 2016). Maltreatment during the first years of life may be especially harmful as it may undermine the safe haven and secure base functions usually provided by caregivers with potential long-term repercussions for the developing attachment relationships (e.g., Lyons-Ruth, Bronfman, \& Parsons, 1999).

Further, we analyzed differences in trajectory groups regarding maternal psychopathology assessed at the child's preschool age. In line with several studies (e.g., Bufferd et al., 2014; Goodman et al., 2011; Luby et al., 2006, 2014), we found the expected higher rate of maternal depressive symptoms among children in the high internalizing symptom trajectory. Comparable to previous studies (Côté et al., 2009; Sterba et al., 2007; Weeks et al., 2014), mothers of children following the high internalizing trajectory reported the highest and mothers of children belonging to the low internalizing trajectory the lowest levels of depressive symptoms, while mothers of children following the moderate internalizing symptom trajectories fell in between. A similar pattern was found regarding maternal somatization and stress, thus extending the literature on predictors for internalizing trajectory classes. As has been discussed earlier (e.g., Goodman et al., 2011; Reinfjell et al., 2016), it is likely that there are multiple complex pathways through which maternal depression, somatization, and stress are associated with the development of internalizing symptoms in offspring, among them genetic (Plomin, 1990), neurobiological (stress regulation system), and social (e.g., modeling and parenting) pathways. As maternal psychopathology and stress are such strong predictors, presumably affecting the child's development through multiple pathways, interventions to reduce maternal depression and stress might prove especially beneficial (cf. Reinfjell et al., 2016).

The analyses of the three broad child temperament dimensions yielded group differences in negative affectivity and surgency. In line with earlier findings (e.g., Nigg, 2006; Reinfjell et al., 2016), children following both low and rising internalizing trajectories showed the lowest levels of negative affectivity at preschool age, children belonging to the moderate trajectory showed intermediate levels, and children following the high internalizing trajectory showed the highest levels. Differences in surgency were much smaller (children following the low internalizing trajectory showed higher surgency than children on all other trajectories) and, unlike previous research (Rothbart et al., 2001), we did not confirm effortful control as a risk factor for internalizing symptoms. However, several studies indicated that low effortful control does not serve as a direct risk factor but interacts with high negative affectivity or low positive affectivity in predicting internalizing symptoms (Gartstein et al., 2012; Hankin, 2012), which was not tested in our study.

An important extension of earlier studies on internalizing trajectories is provided by our assessment of preschool age HPA axis reactivity, a key biological risk mechanism for developmental psychopathology (Bush \& Boyce, 2014; Gunnar \& Quevedo, 2007; Heim, Newport, Mletzko, Miller, \& Nemeroff, 2008). Of note, we found significant differences between internalizing trajectories on cortisol responses to an age-appropriate challenging storytelling task: children belonging to the "stable high" class exhibited the lowest cortisol response, which differed from that of children belonging to the "rising" internalizing symptoms class, who showed the highest cortisol response. As reported above, especially children in the high symptom trajectory experienced high and persistent stress (loss/separation, maltreatment, and maternal mental health problems) beginning early in life. Though also a high proportion of children with rising symptoms were exposed to loss/separation, other stressors such as maltreatment and maternal mental health problems were much lower than in the high stable class. Potentially, cortisol patterns therefore capture the adaptation of the stress-response system that initially upregulates to meet the metabolic demands of the individual under perceived threat, but eventually rebounds to an attenuated response as stress persists and internalizing symptoms become chronic (Jaffee et al., 2015; McEwen, 1998; Miller et al., 2007). At the behavioral level, this potentially maps onto Bowlby's (1980) model of the sequential relationship between anxiety and depression (see Mineka et al., 1998). Extrapolating from this model, anxiety reflects the primary response to separation (protest), which could inflict high metabolic costs, followed by a secondary response when protest proves futile and loss is accepted (despair and resignation), which may resemble attenuated metabolic output.

As such, these data may also help understand the opposing patterns of cortisol reactivity among children with internalizing problems. Thus, enhanced cortisol reactivity among school-aged children and adolescents with internalizing symptoms may particularly characterize the initial formative stages of internalizing symptoms (rising trajectory) as the individual expends resources by engaging and tackling or escaping the stressors (Booij et al., 2013; Cicchetti \& Rogosch, 2001; Dietrich et al., 2013; Harkness et al., 2011; LopezDuran et al., 2009; Ruttle et al., 2011). Conversely, attenuated cortisol secretion may reflect an adaptation of the HPA axis to continuing stress that overwhelms coping capacities eventuating in particularly severe and chronic internalizing symptoms (Badanes et al., 2011; Bae et al., 2015; Harkness et al., 2011).

At the same time, our data are somewhat more difficult to reconcile with a developmental account whereby internalizing problems coincide with hyposecretion of cortisol under stress in prepubertal children, which eventually reverts to hypersecretion in the postpubertal period (Hankin, 2012). As the waves of our current longitudinal study ended in middle 
childhood, we cannot rule out that the pattern of blunted cortisol reactivity that we observed for the high symptom class in the preschool period might shift to a hyperreactive pattern at postpuberty (cf. Hankin et al., 2010). However, we also found a contrasting hyperreactive pattern in early childhood, a pattern that has also been reported in other samples for increased internalizing symptoms at preschool age (e.g., von Klitzing et al., 2012) and in response to early life trauma, such as maltreatment (e.g., Cicchetti \& Rogosch, 2001; Trickett et al., 2010; White et al., 2017). At minimum, this indicates that a hyperreactive HPA axis may characterize a subgroup of (emerging) internalizing disorders, even prepubertally.

Going beyond the separate analyses of a comprehensive set of risk factors, we examined the relative contribution of all significant risk factors in a single analysis (i.e., life events relating to loss/separation and maltreatment experiences before the age of 3, maternal mental health problems, child temperament dimensions surgency and negative affectivity, and cortisol reactivity) comparing the stable low trajectory with all other trajectories. Of these predictors, only the presence of life events relating to loss/separation before the age of 3 differentiated between rising and low internalizing symptom trajectories indicating that this is a predominant factor that may have long-lasting effects leading to a gradual rise of internalizing symptoms to a moderate level until school age.

Several predictors emerged for the moderate symptom trajectory: both higher maternal mental health problems and temperamental factors (lower surgency and higher negative affectivity) at preschool age predicted a stable moderate level of internalizing symptoms. Thus, in the moderate group children may experience their own (temperamental) and familial negative affectivity starting at a young age, which results in a chronically elevated level of "negative mood," without surpassing the clinical threshold at this stage.

Finally, children following the stable high versus stable low trajectories experienced life events relating to loss/separation before the age of 3 , had mothers with higher mental health problems, and showed lower surgency and higher negative affectivity as well as lower cortisol reactivity (trend). These results implicate a multilevel risk mechanism involving an interplay of environmental, neurobiological, and constitutional factors in the early emergence of clinically relevant internalizing symptoms as reflected in the high proportion of anxiety disorders and depression throughout preschool and school age.

Thus, our analyses suggest that each of these predictors encompassing social, individual, and neurobiological vulnerabilities uniquely add to the risk of chronically elevated internalizing symptoms. In contrast, experience of maltreatment did not predict following a high internalizing symptom trajectory, when controlling for other risk factors. In all likelihood, this is partly accounted for by the overlap of maltreatment with other risk factors (as reflected in significant correlations of $r=.31, p<.001$ with maternal mental health problems, $r$ $=.19, p=.004$ with negative affectivity, and $r=.18, p=$ .005 with life events relating to loss/separation), the pure re- liance on maternal reports of maltreatment (as opposed to Child Protection Services files and/or child reports), as well as recruiting our high-risk sample from the community.

In sum, our results are in line with a cumulative risk model (Evans, Li, \& Whipple, 2013): the more risk factors are present, the more mental health problems occur. Thus, the number of risk factors is related to the severity of children's internalizing symptoms. In addition, the risk factors associated with different trajectories also suggest a developmental/temporal relation between risk factors and outcomes. Separation/ loss as a life event in early childhood sets in motion a gradual rise of internalizing symptoms, which lends support to cascade models of development (Masten \& Cicchetti, 2010).

\section{Outcomes at middle elementary school age}

Akin to research in (pre-)adolescents and young adults (Dekker et al., 2007; Sterba et al., 2007; Toumbourou et al., 2011), we examined the outcomes of children belonging to distinct trajectory classes at middle elementary school age, using a comprehensive set of variables and multiple informants (parents, teacher, and children) to determine clinical significance of the high symptoms class. Large group differences were apparent at school age, particularly regarding anxiety and depressive symptoms, anxiety disorders and depression, impairment, and mental health care use.

Among others, trajectory classes differed in the levels of parent-reported specific anxiety and depressive symptoms (with large effect sizes): children in the "stable low" class exhibited the lowest levels, children in the "rising" and "stable moderate" classes exhibited intermediate levels (due to the increasing symptoms in the "rising" class both classes had a similar level of internalizing symptoms at middle elementary school age), and children belonging to the "stable high" class exhibited the highest level of symptoms. In this study we also found that internalizing trajectories differed in terms of anxiety disorders/depression on clinical interviews at school age, thereby extending previous research by underscoring the clinical relevance of different trajectories. As expected, we found that children with low internalizing symptoms predominantly had no disorder, children with moderate internalizing symptoms (i.e., "rising" and "stable moderate" classes) either received no disorder $(46 \%-48 \%)$ or a pure anxiety disorder diagnosis $(35 \%-41 \%)$, whereas the majority of children $(78 \%)$ with stable high internalizing symptoms were diagnosed with an anxiety disorder/depression. The fact that about half of these children had clinical or subclinical depression (mostly comorbid with anxiety disorder, 80\%) and that depression had been highly prevalent in preschool age in this group underscores the clinical relevance of stable high internalizing symptoms. Moreover, these findings mesh well with previous work demonstrating poorer prognosis and higher levels of symptoms and psychosocial impairment in children with comorbid anxiety and depression (Franco, Saavedra, \& Silverman, 2007; Lewinsohn, Rohde, \& Seeley, 1995; von Klitzing et al., 2014). 
Trajectory classes also differed in the levels of parent-reported externalizing symptoms (conduct problems, hyperactivity, and peer problems; medium effect sizes), with higher internalizing symptoms co-occurring with higher externalizing symptoms. Of note, however, even the children with the highest symptom load manifested, on average, externalizing symptoms below the borderline cutoff of the SDQ (Goodman, 1997), indicating that children predominantly suffered from internalizing symptoms.

In contrast to parent reports, children's reports of internalizing symptoms on puppet interviews yielded only a marginally significant difference between classes (with small effect size) and no differences in externalizing symptoms. This finding meshes well with previous work, showing that self-reports of young children only partly distinguish children with more and less severe internalizing symptoms (von Klitzing et al., 2014). Potentially, even school children may still have limited cognitive capacities to impart typical depressive symptoms that require introspection (e.g., feeling worthless) or retrospective reporting (e.g., decreased interest or pleasure). Of note, for ratings of psychiatric symptoms, the overlap between different informants is often particularly low because informants have different perspectives and may refer to different contexts (Kraemer et al., 2003). Our finding is therefore consistent with previous work reporting low agreement between parents and children, especially regarding internalizing symptoms/disorders (for a review, see Grills \& Ollendick, 2002).

As another outcome measure of the individuals' functioning at middle elementary school age, teachers reported on the children's self- and other-oriented social competences. Consistent with findings that deficits in self-oriented social skills (e.g., assertiveness and social participation) are associated with internalizing symptoms (Groeben et al., 2011; Perren et al., 2012), we found class differences on this dimension, but not with respect to other-oriented social competences (e.g., prosocial and cooperative behavior). Children belonging to the "stable low" class had higher self-oriented social skills than children belonging to the other three classes with moderate to high internalizing symptoms (with small effect size). Our findings are in accordance with previous work describing lower social skills in higher internalizing trajectory classes (Korhonen et al., 2014). Distinguishing the two dimensions of social skills might also be useful to shed light on inconsistent findings regarding social skills and internalizing symptom trajectories in earlier studies (Fanti \& Henrich, 2010; Nantel-Vivier et al., 2014).

Moreover, trajectory classes differed in the levels of social impairment such that the high internalizing symptoms, in particular, coincided with distress and/or interfered with the child's everyday life, in keeping with Whalen et al.'s (2016) study. Consistently, children with stable high internalizing symptoms also evidenced the highest rate of mental health care use, comparable to findings by Dekker et al. (2007) in adult women. The rate of mental health care use $(35 \%)$ in this group of children was somewhat higher than what is usually reported for children in school age with mental health problems (25\%-29\%; Hintzpeter et al., 2015; Wichstrøm et al., 2014). Previous work connects social impairment and internalizing symptoms to high levels of help and reassurance seeking (Ford et al., 2008; Goodman, 1999; Joiner \& Metalsky, 2001) due to high levels of insecurity and safety desires. By comparison, only $7 \%-10 \%$ of children with moderate internalizing symptoms at school age seek psychological treatment, although over half were diagnosed with an anxiety disorder/depression, predominantly a pure anxiety disorder though, which has been reported to be less impairing than comorbid conditions (Bufferd, Dougherty, Carlson, \& Klein, 2011; Franco et al., 2007; von Klitzing et al., 2014).

\section{Strengths and limitations}

While this study has notable strengths, such as recruitment of a high-risk sample with prospective data, multilevel and multi-informant data, including state-of-the-art diagnostic interviews, and assessment of a comprehensive set of risk/ maintenance factors, some limitations deserve attention. First, the distinct trajectory classes of internalizing symptoms were derived from maternal reports only. Moreover, mothers also reported on life events, their own mental health problems, and the child's temperament, and predominantly mothers served as interviewees regarding their child's clinical diagnoses and maltreatment experiences. Therefore, shared method variance may have potentially inflated associations between trajectory classes and some risk factors. However, the trajectory classes were identified using up to four prospective assessments, were validated using father and teacher reports, and were independently related to objective neurobiological assessments. Moreover, we used structured, interviewer-based interviews (to assess disorders and maltreatment) in which a trained coder makes the decision of whether or not a symptom is present/maltreatment took place. Further, in the case of the outcomes of trajectory classes, we used a combination of mother and father reports, as well as teacher and child reports, which generally confirmed the pattern derived from maternal reports.

Second, a methodological limitation of our study concerns the age bands, which were not optimally saturated between ages 6-7. It follows that any temporary changes that might occur specifically at this age (e.g., due to school entry) may have been suppressed in our trajectories. However, these changes would have occurred against an overall backdrop of continuity as evidenced by the high degree of stability of the internalizing symptom trajectories estimated from wellsaturated age bands prior and subsequent to this age band.

Third, the different risk factors investigated vary in terms of timing. We examined life events relating to the loss of/separation from a significant person and experience of maltreatment before the age of 3 , while maternal mental health problems, child temperament, and stress reactivity were assessed at preschool age. Hence, we cannot rule out that the effects of the risk factors vary by developmental timing and therefore effects and timing of the risk factors may be confounded. 
Fourth, the "stable high" internalizing symptom trajectory descriptively showed a slight nonsignificant decrease in internalizing symptoms over time, which may be due to two reasons. On the one hand, this decrease potentially may have occurred due to mental health interventions, which are readily available to families in the country where this study took place and were sometimes even recommended by our research staff for ethical reasons if parents reported high psychiatric symptoms and impairment of their child during diagnostic interviews. However, rates of mental health care use among participating families were only slightly higher than those usually reported for mental health problems. On the other hand, given that dropout rates in the "stable high" and "stable moderate" classes exceeded those of other classes, with parents often feeling too burdened to attend another assessment, differential attrition may have potentially contributed to the observed decrease. Yet, it is important to note that regardless of this slight decrease, a persistent and pervasive burden prevailed in the high symptom trajectory as evidenced by the high symptom load and the presence of disorders at school age.

\section{Conclusion}

In summary, we identified four distinct trajectory classes of internalizing symptoms from preschool until middle elementary school age. Three of them showed a stable course of low, moderate, and high internalizing symptoms, while a fourth trajectory followed an increasing course. These pathways and outcomes at school age underscore the importance of tak-

\section{References}

Achenbach, T. M., Conners, C. K., Quay, H. C., Verhulst, F. C., \& Howell, C. T. (1989). Replication of empirically derived syndromes as a basis for taxonomy of child/adolescent psychopathology. Journal of Abnormal Child Psychology, 17, 299-323. doi:10.1007/BF00917401

Badanes, L. S., Watamura, S. E., \& Hankin, B. L. (2011). Hypocortisolism as a potential marker of allostatic load in children: Associations with family risk and internalizing disorders. Development and Psychopathology, 23, 881-896. doi:10.1017/s095457941100037x

Bae, Y. J., Stadelmann, S., Klein, A. M., Jaeger, S., Hiemisch, A., Kiess, W., ... Döhnert, M. (2015). The hyporeactivity of salivary cortisol at stress test (TSST-C) in children with internalizing or externalizing disorders is contrastively associated with $\alpha$-amylase. Journal of Psychiatric Research, 71, 78-88. doi:10.1016/j.jpsychires.2015.09.013

Barkmann, C., Erhart, M., Schulte-Markwort, M., \& BELLA study group. (2008). The German version of the Centre for Epidemiological Studies Depression Scale for Children (CES-DC): Psychometric evaluation in a population-based survey of 7 to 17 years old children and adolescents-Results of the BELLA study. European Child and Adolescent Psychiatry, 17(Suppl. 1), 116-124. doi:10.1007/s00787-008-1013-0

Barnett, D., Manly, J. T., \& Cicchetti, D. (1993). Defining child maltreatment: The interface between policy and research. In D. Cicchetti \& S. L. Toth (Eds.), Child abuse, child development, and social policy ( $\mathrm{pp}$. 7-73). Norwood, NJ: Ablex.

Bayer, J. K., Ukoumunne, O. C., Mathers, M., Wake, M., Abdi, N., \& Hiscock, H. (2012). Development of children's internalising and externalising problems from infancy to five years of age. Australian and New Zealand Journal of Psychiatry, 46, 659-668. doi:10.1177/ 0004867412450076

Birmaher, B., Brent, D. A., Chiappetta, L., Bridge, J., Monga, S., \& Baugher, M. (1999). Psychometric properties of the Screen for Child Anxiety Related Emotional Disorders (SCARED): A replication study. Journal of ing early childhood onset of internalizing symptoms seriously. Life events of loss/separation, early maltreatment experiences, maternal psychopathology, child temperament, and neurobiological stress-hyporeactivity emerged as predictors of stable high internalizing trajectories and thus may serve as early markers of risk and important aetiological factors involved in sculpting a distinct ecophenotype at risk of chronic internalizing symptoms (Teicher \& Samson, 2013). Moreover, our data imply that stressful life events, maltreatment, and parental mental health problems are promising targets for prevention and interventions for this group. However, as a large proportion of children of the stable moderate internalizing trajectory also manifested anxiety disorders/depression, experienced early maltreatment, and showed symptoms and impairment at elementary school age, this group may also require prevention/intervention. In contrast to the stable high internalizing trajectory, the rising internalizing symptom trajectory was characterized by hypercortisolism at preschool age, and also a considerable proportion was exposed to loss/separation in early childhood. Although these children only reached a moderate level of symptoms at school age, a risk of further increasing symptoms in later development is conceivable, thus calling for further follow-ups into adolescence. Finally, the present data lead us to conclude that high internalizing symptoms in preschool age require close monitoring and, if necessary, early psychotherapeutic intervention (e.g., Göttken, White, Klein, \& von Klitzing, 2014; Luby, Lenze, \& Tillman, 2012), especially when additional risk factors are present. the American Academy of Child \& Adolescent Psychiatry, 38, 12301236. doi:10.1097/00004583-199910000-00011

Birmaher, B., Khetarpal, S., Brent, D., Cully, M., Balach, L., Kaufman, J., \& Neer, S. M. (1997). The Screen for Child Anxiety Related Emotional Disorders (SCARED): Scale construction and psychometric characteristics. Journal of the American Academy of Child \& Adolescent Psychiatry, 36, 545-553. doi:10.1097/00004583-199704000-00018

Bongers, I. L., Koot, H. M., van der Ende, J., \& Verhulst, F. C. (2003). The normative development of child and adolescent problem behavior. Journal of Abnormal Psychology, 112, 179-192. doi:10.1037/0021843X.112.2.179

Booij, S. H., Bouma, E. M., de Jonge, P., Ormel, J., \& Oldehinkel, A. J. (2013). Chronicity of depressive problems and the cortisol response to psychosocial stress in adolescents: The TRAILS study. Psychoneuroendocrinology, 38, 659-666. doi:10.1016/j.psyneuen.2012.08.004

Bowlby, J. (1980). Attachment and loss. New York: Basic Books.

Bufferd, S. J., Dougherty, L. R., Carlson, G. A., \& Klein, D. N. (2011). Parent-reported mental health in preschoolers: Findings using a diagnostic interview. Comprehensive Psychiatry, 52, 359-369. doi:10.1016/ j.comppsych.2010.08.006

Bufferd, S. J., Dougherty, L. R., Carlson, G. A., Rose, S., \& Klein, D. N (2012). Psychiatric disorders in preschoolers: Continuity from ages 3 to 6. American Journal of Psychiatry, 169, 1157-1164. doi:10.1176/appi.ajp.2012.12020268

Bufferd, S. J., Dougherty, L. R., Olino, T. M., Dyson, M. W., Laptook, R. S. Carlson, G. A., \& Klein, D. N. (2014). Predictors of the onset of depression in young children: A multi-method, multi-informant longitudinal study from ages 3 to 6. Journal of Child Psychology and Psychiatry, 55, 1279-1287. doi:10.1111/jcpp.12252

Bush, N. R., \& Boyce, W. T. (2014). The contributions of early experience to biological development and sensitivity to context. In R. Lewis \& D. Ru- 
dolph (Eds.), Handbook of developmental psychopathology (pp. 287309). New York: Springer.

Cicchetti, D., \& Lynch, M. (1993). Toward an ecological/transactional model of community violence and child maltreatment: Consequences for children's development. Psychiatry, 56, 96-118. doi:10.1080/00332747. 1993.11024624

Cicchetti, D., \& Natsuaki, M. N. (2014). Multilevel developmental perspectives toward understanding internalizing psychopathology: Current research and future directions. Development and Psychopathology, 26(4, Pt. 2), 1189-1190. doi:10.1017/S0954579414000959

Cicchetti, D., \& Rogosch, F. A. (2001). Diverse patterns of neuroendocrine activity in maltreated children. Development and Psychopathology, 13, 677-693. doi:10.1017/S0954579401003145

Cicchetti, D., \& Toth, S. L. (2015). Child maltreatment. In R. M. Lerner (Ed.), Handbook of child psychology and developmental science (pp. 513-563). Hoboken, NJ: Wiley.

Cicchetti, D., Toth, S. L., \& Manly, J. T. (2003). Maternal Maltreatment Classification Interview. Rochester, NY: University of Rochester, Mt. Hope Family Center.

Cicchetti, D., \& Valentino, K. (2006). An ecological-transactional perspective on child maltreatment: Failure of the average expectable environment and its influence on child development. In D. Cicchetti \& D. J. Cohen (Eds.), Developmental psychopathology (2nd ed., pp. 129-201). Hoboken, NJ: Wiley.

Compas, B. E., Connor-Smith, J., \& Jaser, S. S. (2004). Temperament, stress reactivity, and coping: Implications for depression in childhood and adolescence. Journal of Clinical Child and Adolescent Psychology, 33, 2131. doi:10.1207/S15374424JCCP3301_3

Coplan, R. J., \& Ooi, L. (2013). Young children's peer relations: Links with early developing anxiety and depression. In R. E. Tremblay, M. Boivin, \& R. D. V. Peters (Eds.), Encyclopedia on early childhood development [online]. http://www.child-encyclopedia.com/anxiety-and-depression/ according-experts/young-childrens-peer-relations-links-early-developing

Côté, S. M., Boivin, M., Liu, X. C., Nagin, D. S., Zoccolillo, M., \& Tremblay, R. E. (2009). Depression and anxiety symptoms: Onset, developmental course and risk factors during early childhood. Journal of Child Psychology and Psychiatry, 50, 1201-1208. doi:10.1111/j.14697610.2009.02099.x

Davis, S., Votruba-Drzal, E., \& Silk, J. S. (2015). Trajectories of internalizing symptoms from early childhood to adolescence: Associations with temperament and parenting. Social Development, 24, 501-520. doi:10. $1111 /$ sode. 12105

Dekker, M. C., Ferdinand, R. F., van Lang, N. D., Bongers, I. L., van der Ende, J., \& Verhulst, F. C. (2007). Developmental trajectories of depressive symptoms from early childhood to late adolescence: Gender differences and adult outcome. Journal of Child Psychology and Psychiatry, 48, 657-666. doi:10.1111/j.1469-7610.2007.01742.x

Dietrich, A., Ormel, J., Buitelaar, J. K., Verhulst, F. C., Hoekstra, P. J., \& Hartman, C. A. (2013). Cortisol in the morning and dimensions of anxiety, depression, and aggression in children from a general population and clinicreferred cohort: An integrated analysis. The TRAILS study. Psychoneuroendocrinology, 38, 1281-1298. doi:10.1016/j.psyneuen.2012. 11.013

Doom, J. R., \& Gunnar, M. R. (2013). Stress physiology and developmental psychopathology: Past, present, and future. Development and Psychopathology, 25(4, Pt. 2), 1359-1373. doi:10.1017/S0954579413000667

Edwards, S. L., Rapee, R. M., \& Kennedy, S. (2010). Prediction of anxiety symptoms in preschool-aged children: Examination of maternal and paternal perspectives. Journal of Child Psychology and Psychiatry, 51, 313-321. doi:10.1111/j.1469-7610.2009.02160.x

Egger, H. L., \& Angold, A. (2004). The Preschool Age Psychiatric Assessment (PAPA): A structured parent interview for diagnosing psychiatric disorders in preschool children. In C. DelCarmen-Wiggins (Ed.), Handbook of infant, toddler, and preschool mental health assessment (pp. 223-243). New York: Oxford University Press.

Egger, H. L., \& Angold, A. (2006). Common emotional and behavioral disorders in preschool children: Presentation, nosology, and epidemiology. Journal of Child Psychology and Psychiatry, 47, 313-337. doi:10.1111/ j.1469-7610.2006.01618.x

Emde, R. N., Wolf, D., \& Oppenheim, D. (Eds.) (2003). Revealing the inner worlds of young children: The MacArthur Story Stem Battery and parentchild narratives. New York: Oxford University Press.

Evans, G. W., Li, D., \& Whipple, S. S. (2013). Cumulative risk and child development. Psychological Bulletin, 139, 1342-1396. doi:10.1037/ a0031808
Fanti, K. A., \& Henrich, C. C. (2010). Trajectories of pure and co-occurring internalizing and externalizing problems from age 2 to age 12: Findings from the National Institute of Child Health and Human Development Study of Early Child Care. Developmental Psychology, 46, 1159-1175. doi:10.1037/a0020659

Fendrich, M., Weissman, M. M., \& Warner, V. (1990). Screening for depressive disorder in children and adolescents: Validating the Center for Epidemiologic Studies Depression Scale for Children. American Journal of Epidemiology, 131, 538-551. doi:10.1093/oxfordjournals.aje.a115529

Field, A. (2013). Discovering statistics using IBM SPSS Statistics (4th ed.). London: Sage.

Fisher, P. A. (2017). Commentary: Is there a there there in hair? A reflection on child maltreatment and hair cortisol concentrations in White et al. (2017). Journal of Child Psychology and Psychiatry, 58, 1008-1010. doi:10.1111/jcpp.12719

Ford, T., Hamilton, H., Meltzer, H., \& Goodman, R. (2008). Predictors of service use for mental health problems among British schoolchildren. Child and Adolescent Mental Health, 13, 32-40. doi:10.1111/j.14753588.2007.00449.x

Franco, X., Saavedra, L. M., \& Silverman, W. K. (2007). External validation of comorbid patterns of anxiety disorders in children and adolescents. Journal of Anxiety Disorders, 21, 717-729. doi:10.1016/j.janxdis. 2006.10 .002

Fries, E., Hesse, J., Hellhammer, J., \& Hellhammer, D. H. (2005). A new view on hypocortisolism. Psychoneuroendocrinology, 30, 1010-1016. doi:10.1016/j.psyneuen.2005.04.006

Furniss, T., Beyer, T., \& Müller, J. M. (2009). Impact of life events on child mental health before school entry at age six. European Child and Adolescent Psychiatry, 18, 717-724. doi:10.1007/s00787-009-0013-z

Gartstein, M. A., Putnam, S. P., \& Rothbart, M. K. (2012). Etiology of preschool behavior problems: Contributions of temperament attributes in early childhood. Infant Mental Health Journal, 33, 197-211. doi:10. $1002 / \mathrm{imhj} .21312$

Gazelle, H., \& Ladd, G. W. (2003). Anxious solitude and peer exclusion: A diathesis-stress model of internalizing trajectories in childhood. Child Development, 74, 257-278. doi:10.1111/1467-8624.00534

Godinet, M. T., Li, F., \& Berg, T. (2014). Early childhood maltreatment and trajectories of behavioral problems: Exploring gender and racial differences. Child Abuse \& Neglect, 38, 544-556. doi:10.1016/j.chiabu. 2013.07.018

Goodman, R. (1997). The Strengths and Difficulties Questionnaire: A research note. Journal of Child Psychology and Psychiatry, 38, 581-586. doi:10.1111/j.1469-7610.1997.tb01545.x

Goodman, R. (1999). The extended version of the Strengths and Difficulties Questionnaire as a guide to child psychiatric caseness and consequent burden. Journal of Child Psychology and Psychiatry, 40, 791-799. doi:10.1111/1469-7610.00494

Goodman, R. (2001). Psychometric properties of the Strengths and Difficulties Questionnaire. Journal of the American Academy of Child \& Adolescent Psychiatry, 40, 1337-1345. doi:10.1097/00004583-20011100000015

Goodman, S. H., Rouse, M. H., Connell, A. M., Broth, M. R., Hall, C. M., \& Heyward, D. (2011). Maternal depression and child psychopathology: A meta-analytic review. Clinical Child and Family Psychology Review, 14, 1-27. doi:10.1007/s10567-010-0080-1

Göttken, T., White, L. O., Klein, A. M., \& von Klitzing, K. (2014). Shortterm psychoanalytic child therapy for anxious children: A pilot study. Psychotherapy, 51, 148-158. doi:10.1037/a0036026

Grills, A. E., \& Ollendick, T. H. (2002). Issues in parent-child agreement: The case of structured diagnostic interviews. Clinical Child and Family Psychology Review, 5, 57-83. doi:10.1023/A:1014573708569

Groeben, M., Perren, S., Stadelmann, S., \& von Klitzing, K. (2011). Emotional symptoms from kindergarten to middle childhood: Associations with self- and other-oriented social skills. European Child and Adolescent Psychiatry, 20, 3-15. doi:10.1007/s00787-010-0139-z

Gunnar, M., \& Quevedo, K. (2007). The neurobiology of stress and development. Annual Review of Psychology, 58, 145-173. doi:10.1146/annurev.psych.58.110405.085605

Gunnar, M. R., Talge, N. M., \& Herrera, A. (2009). Stressor paradigms in developmental studies: What does and does not work to produce mean increases in salivary cortisol. Psychoneuroendocrinology, 34, 953-967. doi:10.1016/j.psyneuen.2009.02.010

Hankin, B. L. (2012). Future directions in vulnerability to depression among youth: Integrating risk factors and processes across multiple levels of 
analysis. Journal of Clinical Child and Adolescent Psychology, 41, 695718. doi:10.1080/15374416.2012.711708

Hankin, B. L., Badanes, L. S., Abela, J. R. Z., \& Watamura, S. E. (2010). Hypothalamic-pituitary-adrenal axis dysregulation in dysphoric children and adolescents: Cortisol reactivity to psychosocial stress from preschool through middle adolescence. Biological Psychiatry, 68, 484-490. doi:10.1016/j.biopsych.2010.04.004

Harkness, K. L., Stewart, J. G., \& Wynne-Edwards, K. E. (2011). Cortisol reactivity to social stress in adolescents: Role of depression severity and child maltreatment. Psychoneuroendocrinology, 36, 173-181. doi:10.1016/j.psyneuen.2010.07.006

Hastings, P. D., Helm, J., Mills, R. S. L., Serbin, L. A., Stack, D. M., \& Schwartzman, A. E. (2015). Dispositional and environmental predictors of the development of internalizing problems in childhood: Testing a multilevel model. Journal of Abnormal Child Psychology, 43, 831845. doi:10.1007/s10802-014-9951-0

Hatzinger, M., Brand, S., Perren, S., von Wyl, A., von Klitzing, K., \& Holsboer-Trachsler, E. (2007). Hypothalamic-pituitary-adrenocortical (HPA) activity in kindergarten children: Importance of gender and associations with behavioral/emotional difficulties. Journal of Psychiatric Research, 41, 861-870. doi:10.1016/j.jpsychires.2006.07.012

Hawker, D. S. J., \& Boulton, M. J. (2000). Twenty years' research on peer victimization and psychosocial maladjustment: A meta-analytic review of cross-sectional studies. Journal of Child Psychology and Psychiatry, 41, 441-455. doi:10.1111/1469-7610.00629

Heim, C., Newport, D. J., Mletzko, T., Miller, A. H., \& Nemeroff, C. B. (2008). The link between childhood trauma and depression: Insights from HPA axis studies in humans. Psychoneuroendocrinology, 33, 693-710. doi:10.1016/j.psyneuen.2008.03.008

Hintzpeter, B., Klasen, F., Schön, G., Voss, C., Hölling, H., \& Ravens-Sieberer, U. (2015). Mental health care use among children and adolescents in Germany: Results of the longitudinal BELLA study. European Child and Adolescent Psychiatry, 24, 705-713. doi:10.1007/s00787015-0676-6

Jaffee, S. R., McFarquhar, T., Stevens, S., Ouellet-Morin, I., Melhuish, E., \& Belsky, J. (2015). Interactive effects of early and recent exposure to stressful contexts on cortisol reactivity in middle childhood. Journal of Child Psychology and Psychiatry, 56, 138-146. doi:10.1111/jcpp.12287

Joiner, T. E., \& Metalsky, G. I. (2001). Excessive reassurance seeking: Delineating a risk factor involved in the development of depressive symptoms. Psychological Science, 12, 371-378. doi:10.1111/1467-9280. 00369

Keiley, M. K., Howe, T. R., Dodge, K. A., Bates, J. E., \& Pettit, G. S. (2001). The timing of child physical maltreatment: A cross-domain growth analysis of impact on adolescent externalizing and internalizing problems. Development and Psychopathology, 13, 891-912.

Kim, J., \& Cicchetti, D. (2006). Longitudinal trajectories of self-system processes and depressive symptoms among maltreated and nonmaltreated children. Child Development, 77, 624-639. doi:10.1111/j.1467-8624. 2006.00894.x

Kim, K. J., Conger, R. D., Elder, G. H., \& Lorenz, F. O. (2003). Reciprocal influences between stressful life events and adolescent internalizing and externalizing problems. Child Development, 74, 127-143. doi:10.1111/ $1467-8624.00525$

Klasen, F., Otto, C., Kriston, L., Patalay, P., Schlack, R., \& Ravens-Sieberer, U. (2015). Risk and protective factors for the development of depressive symptoms in children and adolescents: Results of the longitudinal BELLA study. European Child and Adolescent Psychiatry, 24, 695703. doi:10.1007/s00787-014-0637-5

Klasen, H., Woerner, W., Rothenberger, A., \& Goodman, R. (2003). The German version of the Strengths and Difficulties Questionnaire (SDQDeu)_Overview over first validation and normative studies. Praxis der Kinderpsychologie und Kinderpsychiatrie, 52, 491-502.

Klein, A. M., Otto, Y., Fuchs, S., Reibiger, I., \& von Klitzing, K. (2015). A prospective study of behavioral and emotional symptoms in preschoolers. European Child and Adolescent Psychiatry, 24, 291-299. doi:10.1007/ s00787-014-0575-2

Klein, A. M., Otto, Y., Fuchs, S., Zenger, M., \& von Klitzing, K. (2013). Psychometric properties of the parent-rated SDQ in preschoolers. European Journal of Psychological Assessment, 29, 96-104. doi:10.1027/10155759/a000129

Korhonen, M., Luoma, I., Salmelin, R. K., Helminen, M., Kaltiala-Heino, R., \& Tamminen, T. (2014). The trajectories of child's internalizing and externalizing problems, social competence and adolescent self-reported problems in a Finnish normal population sample. School Psychology International, 35, 561-579. doi:10.1177/0143034314525511

Kraemer, H. C., Measelle, J. R., Ablow, J. C., Essex, M. J., Boyce, W. T., \& Kupfer, D. J. (2003). A new approach to integrating data from multiple informants in psychiatric assessment and research: Mixing and matching contexts and perspectives. American Journal of Psychiatry, 160, 15661577. doi:10.1176/appi.ajp.160.9.1566

Lauterbach, D., \& Armour, C. (2016). Symptom trajectories among child survivors of maltreatment: Findings from the Longitudinal Studies of Child Abuse and Neglect (LONGSCAN). Journal of Abnormal Child Psychology, 44, 369-379. doi:10.1007/s10802-015-9998-6

Lewinsohn, P. M., Rohde, P., \& Seeley, J. R. (1995). Adolescent psychopathology: III. The clinical consequences of comorbidity. Journal of the American Academy of Child \& Adolescent Psychiatry, 34, 510-519. doi:10.1097/00004583-199504000-00018

Lopez-Duran, N. L., Kovacs, M., \& George, C. J. (2009). Hypothalamic-pituitary-adrenal axis dysregulation in depressed children and adolescents: A meta-analysis. Psychoneuroendocrinology, 34, 1272-1283. doi:10. 1016/j.psyneuen.2009.03.016

Lubke, G., \& Muthén, B. O. (2007). Performance of factor mixture models as a function of model size, covariate effects, and class-specific parameters. Structural Equation Modeling, 14, 26-47. doi:10.1207/ s15328007sem1401_2

Luby, J. L., Belden, A. C., \& Spitznagel, E. (2006). Risk factors for preschool depression: The mediating role of early stressful life events. Journal of Child Psychology and Psychiatry, 47, 1292-1298. doi:10.1111/j.14697610.2006.01672.x

Luby, J. L., Gaffrey, M. S., Tillman, R., April, L. M., \& Belden, A. C. (2014). Trajectories of preschool disorders to full DSM depression at school age and early adolescence: Continuity of preschool depression. American Journal of Psychiatry, 171, 768-776. doi:10.1176/appi.ajp.2014. 13091198

Luby, J. L., Lenze, S., \& Tillman, R. (2012). A novel early intervention for preschool depression: Findings from a pilot randomized controlled trial. Journal of Child Psychology and Psychiatry, 53, 313-322. doi:10.1111/ j.1469-7610.2011.02483.x

Lyons-Ruth, K., Bronfman, E., \& Parsons, E. (1999). Maternal frightened, frightening, or atypical behavior and disorganized infant attachment patterns. Monographs of the Society for Research in Child Development, 64 , 67-96. doi:10.1111/1540-5834.00034

Manly, J. T., Kim, J. E., Rogosch, F. A., \& Cicchetti, D. (2001). Dimensions of child maltreatment and children's adjustment: Contributions of developmental timing and subtype. Development and Psychopathology, 13, $759-782$

Masten, A. S., \& Cicchetti, D. (2010). Developmental cascades. Development and Psychopathology, 22, 491-495. doi:10.1017/S09545794 10000222

McEwen, B. S. (1998). Protective and damaging effects of stress mediators. New England Journal of Medicine, 338, 171-179. doi:10.1056/ NEJM199801153380307

Measelle, J. R., Ablow, J. C., Cowan, P. A., \& Cowan, C. P. (1998). Assessing young children's views of their academic, social, and emotional lives: An evaluation of the self-perception scales of the Berkeley Puppet Interview. Child Development, 69, 1556-1576. doi:10.1111/j.14678624.1998.tb06177.x

Mesman, J., \& Koot, H. M. (2000). Child-reported depression and anxiety in preadolescence: I. Associations with parent- and teacher-reported problems. Journal of the American Academy of Child \& Adolescent Psychiatry, 39, 1371-1378. doi:10.1097/00004583-200011000-00011

Miller, G. E., Chen, E., \& Zhou, E. S. (2007). If it goes up, must it come down? Chronic stress and the hypothalamic-pituitary-adrenocortical axis in humans. Psychological Bulletin, 133, 25-45. doi:10.1037/00332909.133.1.25

Mills, R. S. L., Hastings, P. D., Helm, J., Serbin, L. A., Etezadi, J., Stack, D. M., . . L Li, H. H. (2012). Temperamental, parental, and contextual contributors to early-emerging internalizing problems: A new integrative analysis approach. Social Development, 21, 229-253. doi:10.1111/ j.1467-9507.2011.00629.x

Mineka, S., Watson, D., \& Clark, L. A. (1998). Comorbidity of anxiety and unipolar mood disorders. Annual Review of Psychology, 49, 377-412. doi:10.1146/annurev.psych.49.1.377

Muris, P., \& Ollendick, T. H. (2005). The role of temperament in the etiology of child psychopathology. Clinical Child and Family Psychology Review, 8, 271-289. doi:10.1007/s10567-005-8809-y 
Murray, L., Arteche, A., Fearon, P., Halligan, S., Goodyer, I., \& Cooper, P. (2011). Maternal postnatal depression and the development of depression in offspring up to 16 years of age. Journal of the American Academy of Child \& Adolescent Psychiatry, 50, 460-470. doi:10.1016/j.jaac. 2011.02.001

Muthén, B. (2004). Latent variable analysis: Growth mixture modeling and related techniques for longitudinal data. In D. Kaplan (Ed.), Handbook of quantitative methodology for the social sciences (pp. 345-368). Newbury Park, CA: Sage.

Muthén, L. K., \& Muthén, B. O. (1998-2012). Mplus user's guide (7th ed.). Los Angeles: Author.

Nantel-Vivier, A., Pihl, R. O., Côté, S., \& Tremblay, R. E. (2014). Developmental association of prosocial behaviour with aggression, anxiety and depression from infancy to preadolescence. Journal of Child Psychology and Psychiatry, 55, 1135-1144. doi:10.1111/jcpp.12235

Newman, D. L., Moffitt, T. E., Caspi, A., \& Silva, P. A. (1998). Comorbid mental disorders: Implications for treatment and sample selection. Journal of Abnormal Psychology, 107, 305-311.

Nigg, J. T. (2006). Temperament and developmental psychopathology. Journal of Child Psychology and Psychiatry, 47, 395-422. doi:10.1111/ j.1469-7610.2006.01612.x

Nolte, T., Guiney, J., Fonagy, P., Mayes, L. C., \& Luyten, P. (2011). Interpersonal stress regulation and the development of anxiety disorders: An attachment-based developmental framework. Frontiers in Behavioral Neuroscience, 5, 55. doi:10.3389/fnbeh.2011.00055

Nylund, K. L., Asparouhov, T., \& Muthén, B. O. (2007). Deciding on the number of classes in latent class analysis and growth mixture modeling: A Monte Carlo simulation study. Structural Equation Modeling, 14, 535569. doi:10.1080/10705510701575396

O'Connor, T. G. (2016). Developmental models and mechanisms for understanding the effects of early experiences on psychological development. In D. Cicchetti (Ed.), Developmental psychopathology (pp. 156-198). Hoboken, NJ: Wiley.

Otto, Y., Kolmorgen, K., Sierau, S., Weis, S., von Klitzing, K., \& Klein, A. M. (2016). Parenting behaviors of mothers and fathers of preschool age children with internalizing disorders. Journal of Child and Family Studies, 25, 381-395. doi:10.1007/s10826-015-0242-3

Perren, S. (2007). SOCOMP (Self- and Other-oriented social Competences). Ein Fragebogen zur Erfassung von selbst- und fremdorienterten verhaltensbezogenen sozialen Kompetenzen. Manual. Zürich: Universität Zürich, Jacobs Center for Productive Youth Development.

Perren, S., Forrester-Knauss, C., \& Alsaker, F. D. (2012). Self- and otheroriented social skills: Differential associations with children's mental health and bullying roles. Journal for Educational Research Online, 4, 99-123.

Perren, S., Stadelmann, S., Lüdin, J., von Wyl, A., \& von Klitzing, K. (2008). Self-reported symptoms and strengths of children in kindergarten age: Reliability and validity of the German Version of the Berkeley Puppet Interview (Kindergartenkinder schätzen ihre Symptome und Stärken ein: Das Berkeley Puppet Interview in Forschung und Praxis). Kinderanalyse, $16,1-22$.

Plomin, R. (1990). The role of inheritance in behavior. Science, 248, 183188. doi: $10.1126 /$ science. 2183351

Pruessner, J. C., Kirschbaum, C., Meinlschmid, G., \& Hellhammer, D. H. (2003). Two formulas for computation of the area under the curve represent measures of total hormone concentration versus time-dependent change. Psychoneuroendocrinology, 28, 916-931. doi:10.1016/S03064530(02)00108-7

Putnam, S. P., \& Rothbart, M. K. (2006). Development of short and very short forms of the Children's Behavior Questionnaire. Journal of Personality Assessment, 87, 102-112. doi:10.1207/s15327752jpa8701_09

Radloff, L. S. (1977). The CES-D Scale: A self-report depression scale for research in the general population. Applied Psychological Measurement, 1, 385-401. doi:10.1177/014662167700100306

Reinfjell, T., Kårstad, S. B., Berg-Nielsen, T. S., Luby, J. L., \& Wichstrøm, L. (2016). Predictors of change in depressive symptoms from preschool to first grade. Development and Psychopathology, 28, 1517-1530. doi:10.1017/S0954579415001170

Ringoot, A. P., Jansen, P. W., Steenweg-de Graaff, J., Measelle, J. R., van der Ende, J., Raat, H., . . . Tiemeier, H. (2013). Young children's self-reported emotional, behavioral, and peer problems: The Berkeley Puppet Interview. Psychological Assessment, 25, 1273-1285. doi:10.1037/ a0033976

Robinson, L. R., Morris, A. S., Heller, S. S., Scheeringa, M. S., Boris, N. W., \& Smyke, A. T. (2009). Relations between emotion regulation, parenting, and psychopathology in young maltreated children in out of home care Journal of Child and Family Studies, 18, 421-434. doi:10.1007/ s10826-008-9246-6

Rothbart, M. K., Ahadi, S. A., Hershey, K. L., \& Fisher, P. (2001). Investigations of temperament at three to seven years: The Children's Behavior Questionnaire. Child Development, 72, 1394-1408. doi:10.1111/14678624.00355

Rutter, M., Kumsta, R., Schlotz, W., \& Sonuga-Barke, E. (2012). Longitudinal studies using a "natural experiment" design: The case of adoptees from Romanian institutions. Journal of the American Academy of Child \& Adolescent Psychiatry, 51, 762-770. doi:10.1016/j.jaac.2012.05.011

Ruttle, P. L., Shirtcliff, E. A., Serbin, L. A., Ben-Dat Fisher, D., Stack, D. M. \& Schwartzman, A. E. (2011). Disentangling psychobiological mechanisms underlying internalizing and externalizing behaviors in youth: Longitudinal and concurrent associations with cortisol. Hormones and Behavior, 59, 123-132. doi:10.1016/j.yhbeh.2010.10.015

Scheuer, S., Ising, M., Uhr, M., Otto, Y., von Klitzing, K., \& Klein, A. M. (2016). FKBP5 polymorphisms moderate the influence of adverse life events on the risk of anxiety and depressive disorders in preschool children. Journal of Psychiatric Research, 72, 30-36. doi:10.1016/j.jpsychires.2015.10.009

Schleider, J. L., \& Weisz, J. R. (2017). Family process and youth internalizing problems: A triadic model of etiology and intervention. Development and Psychopathology, 29, 273-301. doi:10.1017/S095457941600016X

Shanahan, L., Calkins, S. D., Keane, S. P., Kelleher, R., \& Suffness, R. (2014). Trajectories of internalizing symptoms across childhood: The roles of biological self-regulation and maternal psychopathology. Development and Psychopathology, 26(4, Pt. 2), 1353-1368. doi:10.1017/ S0954579414001072

Shivram, R., Bankart, J., Meltzer, H., Ford, T., Vostanis, P., \& Goodman, R. (2009). Service utilization by children with conduct disorders: Findings from the 2004 Great Britain child mental health survey. European Child and Adolescent Psychiatry, 18, 555-563. doi:10.1007/s00787009-0012-0

Spitzer, R. L., Kroenke, K., Williams, J. B., \& Patient Health Questionnaire Primary Care Study Group. (1999). Validation and utility of a self-report version of PRIME-MD-The PHQ primary care study. Journal of the American Medical Association, 282, 1737-1744. doi:10.1001/ jama.282.18.1737

Sterba, S. K., Prinstein, M. J., \& Cox, M. J. (2007). Trajectories of internalizing problems across childhood: Heterogeneity, external validity, and gender differences. Development and Psychopathology, 19, 345-366. doi:10.1017/s0954579407070174

Stone, L. L., Otten, R., Engels, R. C. M. E., Vermulst, A. A., \& Janssens, J. M. A. M. (2010). Psychometric properties of the parent and teacher versions of the Strengths and Difficulties Questionnaire for 4- to 12-yearolds: A review. Clinical Child and Family Psychology Review, 13, 254-274. doi:10.1007/s10567-010-0071-2

Stone, L. L., Otten, R., Janssens, J. M. A. M., Soenens, B., Kuntsche, E., \& Engels, R. C. M. E. (2013). Does parental psychological control relate to internalizing and externalizing problems in early childhood? An examination using the Berkeley puppet interview. International Journal of Behavioral Development, 37, 309-318. doi:10.1177/01650254 13490865

Task Force on Research Diagnostic Criteria: Infancy and Preschool. (2003). Research diagnostic criteria for infants and preschool children: The process and empirical support. Journal of the American Academy of Child \& Adolescent Psychiatry, 42, 1504-1512. doi:10.1097/00004583200312000-00018

Teicher, M. H., \& Samson, J. A. (2013). Childhood maltreatment and psychopathology: A case for ecophenotypic variants as clinically and neurobiologically distinct subtypes. American Journal of Psychiatry, 170, 1114-1133. doi:10.1176/appi.ajp.2013.12070957

Thompson, R., \& Tabone, J. K. (2010). The impact of early alleged maltreatment on behavioral trajectories. Child Abuse \& Neglect, 34, 907-916. doi:10.1016/j.chiabu.2010.06.006

Toumbourou, J. W., Williams, I., Letcher, P., Sanson, A., \& Smart, D. (2011). Developmental trajectories of internalising behaviour in the prediction of adolescent depressive symptoms. Australian Journal of Psychology, 63, 214-223. doi:10.1111/j.1742-9536.2011.00023.x

Trickett, P. K., Noll, J. G., Susman, E. J., Shenk, C. E., \& Putnam, F. W. (2010). Attenuation of cortisol across development for victims of sexual abuse. Development and Psychopathology, 22, 165-175. doi:10.1017/ S0954579409990332 
van der Vegt, E. J., van der Ende, J., Ferdinand, R. F., Verhulst, F. C., \& Tiemeier, H. (2009). Early childhood adversities and trajectories of psychiatric problems in adoptees: Evidence for long lasting effects. Journal of Abnormal Child Psychology, 37, 239-249. doi:10.1007/s10802-008-9272-2

Vasey, M. W., Bosmans, G., \& Ollendick, T. H. (2014). The developmental psychopathology of anxiety. In R. Lewis \& D. Rudolph (Eds.), Handbook of developmental psychopathology (pp. 543-560). New York: Springer.

von Klitzing, K., Kelsay, K., \& Emde, R. N. (2003). The structure of five-yearold childrens's play narratives within the MacArthur Story Stem Methodology. In R. N. Emde, D. Wolf, \& D. Oppenheim (Eds.), Revealing the inner worlds of young children: The MacArthur Story Stem Battery and parent-child narratives (pp. 106-128). New York: Oxford University Press.

von Klitzing, K., Perren, S., Klein, A. M., Stadelmann, S., White, L. O., Groeben, M., . . . Hatzinger, M. (2012). The interaction of social risk factors and HPA axis dysregulation in predicting emotional symptoms of five- and six-year-old children. Journal of Psychiatric Research, 46, 290-297. doi:10.1016/j.jpsychires.2011.12.004

von Klitzing, K., White, L. O., Otto, Y., Fuchs, S., Egger, H. L., \& Klein, A. M. (2014). Depressive comorbidity in preschool anxiety disorder. Journal of Child Psychology and Psychiatry, 55, 1107-1116. doi:10.1111/ jcpp. 12222

Wadsworth, M. E., \& Achenbach, T. M. (2005). Explaining the link between low socioeconomic status and psychopathology: Testing two mechanisms of the social causation hypothesis. Journal of Consulting and Clinical Psychology, 73, 1146-1153. doi:10.1037/0022-006X.73.6.1146

Weeks, M., Cairney, J., Wild, T. C., Ploubidis, G. B., Naicker, K., \& Colman, I. (2014). Early-life predictors of internalizing symptom trajectories in
Canadian children. Depression and Anxiety, 31, 608-616. doi:10.1002/ da. 22235

Whalen, D. J., Luby, J. L., Tilman, R., Mike, A., Barch, D., \& Belden, A. C. (2016). Latent class profiles of depressive symptoms from early to middle childhood: Predictors, outcomes, and gender effects. Journal of Child Psychology and Psychiatry, 57, 794-804. doi:10.1111/jcpp.12518

White, L. O., Ising, M., von Klitzing, K., Sierau, S., Michel, A., Klein, A. M., . . . Stalder, T. (2017). Reduced hair cortisol after maltreatment mediates externalizing symptoms in middle childhood and adolescence. Journal of Child Psychology and Psychiatry, 58, 998-1007. doi:10.1111/jcpp. 12700

Wichstrøm, L., Belsky, J., \& Berg-Nielsen, T. S. (2013). Preschool predictors of childhood anxiety disorders: A prospective community study. Journal of Child Psychology and Psychiatry, 54, 1327-1336. doi:10.1111/ jcpp. 12116

Wichstrøm, L., Belsky, J., Jozefiak, T., Sourander, A., \& Berg-Nielsen, T. S. (2014). Predicting service use for mental health problems among young children. Pediatrics, 133, 1054-1060. doi:10.1542/peds.2013-3184

Woerner, W., Becker, A., \& Rothenberger, A. (2004). Normative data and scale properties of the German parent SDQ. European Child and Adolescent Psychiatry, 13(Suppl. 2), II3-II10. doi:10.1007/s00787-004-2002-6

Zalsman, G., Brent, D. A., \& Weersing, V. R. (2006). Depressive disorders in childhood and adolescence: An overview: Epidemiology, clinical manifestation and risk factors. Child and Adolescent Psychiatric Clinics of North America, 15, 827-841. doi:10.1016/j.chc.2006.05.002

Zeanah, C. H., Gunnar, M. R., McCall, R. B., Kreppner, J. M., \& Fox, N. A. (2011). Sensitive periods. Monographs of the Society for Research in Child Development, 76, 147-162. doi:10.1111/j.1540-5834.2011.00631.x 